\title{
Polineuromiopatia do paciente crítico: uma revisão da literatura
}

\author{
Polineuromyopathy in the critically ill patient
}

\author{
Victor E. C. Zamora*
}

Mônica R. Cruz

\section{Resumo}

A polineuromiopatia do paciente crítico é uma doença com grande prevalência entre os pacientes internados em unidade de terapia intensiva e expostos aos seus fatores de risco, dentre os quais a sepse possui grande importância. Essa doença provoca redução da funcionalidade do paciente e dificulta sua saída da prótese ventilatória por atingir os nervos e músculos tanto dos membros quanto os ventilatórios, promovendo alterações funcionais no sarcolema e causando redução na sua excitabilidade e perda de fibras musculares tanto do tipo I quanto do tipo II, além de prejudicar a função mitocondrial muscular. A abordagem clínica dos indivíduos com polineuromiopatia do paciente crítico está baseada na identificação da fraqueza generalizada, na exclusão de outras causas de fraqueza muscular extrínsecas à doença crítica e na mensuração da força muscular. O uso da escala do Medical Research Council e da dinamometria de preensão manual são métodos simples de se identificar a fraqueza muscular adquirida na unidade de terapia intensiva. Algumas te- rapêuticas possíveis para a polineuromiopatia do paciente crítico são: o controle estrito da glicemia através da infusão de insulina, o uso cauteloso de bloqueadores neuromusculares e corticosteroides, a reabilitação precoce e o uso de protocolos de desmame da ventilação mecânica invasiva. No entanto, a recuperação do paciente depende de inúmeros fatores, incluindo a idade do indivíduo, a doença de base, comorbidades e o nível de intensidade da reabilitação. A presente revisão da literatura tem o objetivo de descrever as características gerais da lesão neuromuscular decorrentes da polineuromiopatia do paciente crítico, os principais aspectos de sua avaliação clínica e física, a fisiopatologia da falha do desmame ventilatório e as possíveis terapêuticas existentes para essa doença. A equipe multidisciplinar deve estar atenta à presença dessa afecção, com a finalidade de agir precocemente, visando reduzir seus efeitos deletérios.

Descritores: Doenças musculares; Polineuropatias: Desmame do respirador; Modalidades de fisioterapia; Sepse; Unidades de terapia intensiva . 


\section{Abstract}

The critical illness polyneuromyopathy is a high prevalence disease among patients hospitalized in the intensive care unit and exposed to its risk factors, among which sepsis has great importance. This disease causes reduced functionality of the patient and difficulty in getting out from invasive mechanical ventilation, by affecting both nerves and muscles of the limbs as the ventilatory, promoting functional changes in the sarcolemma, causing reduction in their excitability and loss of both muscle fiber type I and type II, as well as affecting muscle mitochondrial function. The clinical management of individuals with critical illness polyneuromyopathy is based on the identification of generalized weakness, exclusion of other causes of muscle weakness extrinsic to critical illness and in measuring muscle strength. The use of the Medical Research Council scale and hand dynamometry are simple methods to identify muscle weakness acquired in the intensive care unit. Some potential therapeutics for critical illness polyneuromyopathy are strict control of blood glucose by insulin infusion, the cautious use of neuromuscular blocking agents and cor- ticosteroids, early rehabilitation and the use of protocols for weaning from invasive mechanical ventilation. However, patient recovery depends on numerous factors, including the individual's age, underlying disease, comorbidities and level of intensity of rehabilitation. This literature review aims to describe the general characteristics of neuromuscular injury arising from critical illness polyneuromyopathy, the key aspects of its clinical and physical evaluation, the pathophysiology of weaning failure and possible existing therapies for this disease. The multidisciplinary team should be alert to the presence of this disease in order to act early and to reduce its deleterious effects.

Keywords: Muscular diseases; Polyneuropathies; Ventilator weaning; Physical therapy modalities; Sepsis; Intensive care units.

\section{Introdução}

A fraqueza muscular é uma complicação frequentemente vista em pacientes críticos internados em unidade de terapia intensiva (UTI), ${ }^{1,2}$ acometendo, em média, $46 \%$ dos pacientes internados nessa unidade e que foram expostos aos seus fatores de risco (Figura 1). ${ }^{3}$ Nos casos

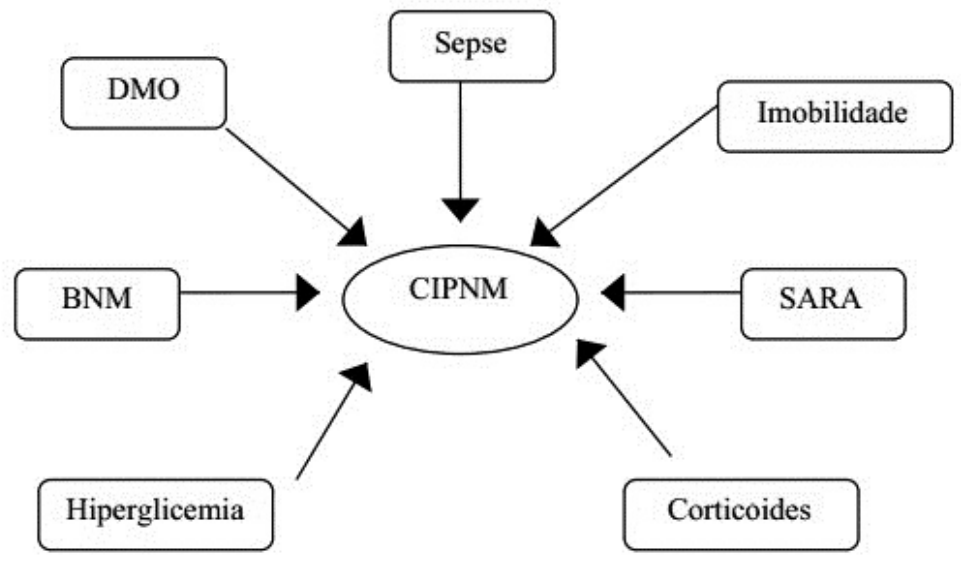

DMO:disfunção múltipla de órgãos; BNM: bloqueador neuromuscular; SARA:síndrome da angústia respiratória aguda. 4,6

Figura 1. Fatores de risco para CIPNM 
de sepse, essa taxa de incidência pode variar entre $70 \%$ e $100 \%{ }^{1}$

Duas doenças distintas têm sido descritas como causadoras de fraqueza generalizada em pacientes críticos: a polineuropatia do paciente crítico (critical illness polyneuropathy - CIP), ${ }^{4}$ que é a polineuropatia aguda mais incidente nesse grupo de pacientes, ${ }^{5}$ e a miopatia do paciente crítico (critical illness myopathy - CIM), ${ }^{4}$ que é o acometimento dos músculos primariamente, sem lesão nervosa. ${ }^{5}$

A diferenciação entre CIP e CIM é difícil de ser realizada, uma vez que muitos dos seus sinais clínicos, eletrofisiológicos e fatores de risco são sobrepostos, ${ }^{4,6}$ além de, frequentemente, ambas coexistirem no mesmo paciente. ${ }^{7}$ Assim, propõe-se a utilização de um termo mais abrangente, como fraqueza adquirida na $\mathrm{UTI}^{6}$ ou polineuromiopatia do paciente crítico (critical illness polyneuromyopathy - CIPNM). ${ }^{8}$ Essa doença tem sido reconhecida como uma das mais prevalentes no paciente crítico em internação prolongada. ${ }^{9}$

CIPNM é uma axonopatia sensitivomotora, ${ }^{8}$ que leva à flacidez e fraqueza muscular dos membros ${ }^{4}$ e à fraqueza nos músculos da parede torácica, ${ }^{10}$ podendo ter ou não alteração dos reflexos profundos, ${ }^{6} \mathrm{da}$ sensibilidade superficial e profunda, e da dor nas extremidades. ${ }^{7}$ Esse termo define a fraqueza clinicamente detectável em pacientes críticos, quando não há outra etiologia confirmada senão a doença crítica. ${ }^{7}$

A CIPNM adiciona morbidade ao paciente crítico, ${ }^{8,11}$ se relaciona diretamente com sua mortalidade, ${ }^{2,12}$ promove a dependência da ventilação mecânica invasiva (VMI), ${ }^{10} \mathrm{o}$ aumento do tempo de internação hospitalar, ${ }^{12}$ a redução da qualidade de vida após a alta nosocomial e a necessidade de reabilitação por períodos prolongados. ${ }^{11}$

A presente revisão da literatura tem o objetivo de descrever as características gerais da lesão neuromuscular decorrentes da CIPNM, os principais aspectos de sua avaliação clínica e física, a fisiopatologia da falha do desmame ventilatório e as possíveis terapêuticas existentes para essa doença.

\section{Aspectos da avaliação clínica e física da CIPNM}

Pacientes portadores de CIPNM são reconhecidos, principalmente, por duas características que podem ocorrer simultaneamente: a fraqueza muscular generalizada e o desmame difícil da VMI. ${ }^{1,4,6}$ Esses achados são encontrados independentemente da recuperação do nível de consciência e da melhor evolução clínica.,

A abordagem clínica dos indivíduos com CIPNM está baseada na identificação da fraqueza generalizada, na exclusão de outras causas de fraqueza muscular extrínsecas à doença crítica e na mensuração da força muscular. A revisão da história patológica pregressa, a análise cuidadosa do curso dos sintomas neuromusculares e a investigação da exposição aos seus fatores de risco, podem ser úteis. ${ }^{7} \mathrm{O}$ exame físico depende da cooperação e do esforço máximo do paciente, ${ }^{6}$ e pode ter limitações e dificuldades inerentes ao quadro clínico do indivíduo., ${ }^{4,6} \mathrm{O}$ exame neurológico deve incluir o nível de consciência e a função cognitiva, a avaliação dos nervos cranianos, da motricidade e sensibilidade, dos reflexos tendinosos, da coordenação motora, do tônus e do trofismo muscular. ${ }^{7}$

A fraqueza muscular generalizada nessa doença é simétrica e possui início repentino, podendo variar desde uma tetraparesia a uma tetraplegia flácidas. ${ }^{4,6}$ A CIPNM pode afetar mais os membros inferiores que os superiores, ${ }^{1}$ e acometer mais os músculos proximais que os distais. ${ }^{8}$ A ausência prévia de doença do sistema nervoso central (SNC) ou do sistema nervoso periférico (SNP) alerta para o possível diagnóstico no paciente cooperativo e sem sedação, que permanece hipomóvel ou imóvel no leito e com grau de força muscular baixo. ${ }^{13}$ Entretanto, a CIPNM pode surgir também em doentes que já possuíam lesão do SNC prévia à internação na UTI. ${ }^{14}$ Caso o paciente apresente déficit focal neurológico específico, exames complementares são necessários para identificação de lesões do 


\section{SNC ou SNP. 6}

O meio de investigação mais simples, sendo utilizado como linha de frente para a identificação dessa doença, é a escala do Medical Research Council (MRC), ${ }^{10}$ que fornece uma visão global da função motora. A escala deve ser utilizada tão logo seja possível, conforme colaboração do paciente. ${ }^{7}$ A avaliação pela escala do MRC consiste na análise de seis movimentos específicos (Quadro 1), através do teste muscular manual, pontuando-os de zero (plegia) a cinco (vence grande resistência manual); soma-se o grau de força muscular de todos os grupos musculares testados, com pontuação máxima de 60 pontos. Caso o paciente esteja impossibilitado de ter um dos membros testados (por exemplo: amputação), assume-se que este teria a mesma força do membro contralateral. ${ }^{9}$

A pontuação indicativa de CIPNM é de 48 pontos ou menos. ${ }^{8}$ Indivíduos que têm a pontuação entre 48 e 37 pontos na escala do MRC são considerados portadores de fraqueza significativa; os que apresentam 36 pontos ou menos são classificados como severamente fracos. ${ }^{15} \mathrm{~A}$ mortalidade aumenta conforme mais fraco é o paciente. ${ }^{2}$ Caso a avaliação pelo MRC indique CIPNM, uma reavaliação é feita 24 horas depois para confirmação do diagnóstico. ${ }^{7}$

O escore do MRC pode ser afetado pelo posicionamento do paciente. ${ }^{7}$ Dessa forma, a padronização da posição na avaliação pode minimizar vieses inter e intra-avaliadores. No nosso serviço de fisioterapia na UTI Geral do Hospital Universitário Pedro Ernesto, a avaliação do MRC é feita em decúbito dorsal, com a cabeceira o mais elevada possível (pelo menos entre $45^{\circ}$ a $60^{\circ}$ ) e postura simétrica. Primeira-

\section{Quadro 1. Movimentos avaliados na escala do MRC $^{6}$}

\begin{tabular}{|c|c|}
\hline \multicolumn{2}{|c|}{ Movimentos solicitados } \\
\hline Membros superiores & Membros inferiores \\
\hline - Ombro: abdução & - Quadril: flexão \\
\hline - Cotovelo: flexão & - Joelho: extensão \\
\hline - Punho: flexão & - Tornozelo: dorsiflexão \\
\hline
\end{tabular}

mente o movimento é testado de forma livre. De acordo com o resultado, é imposta resistência manual ou eliminada a ação da gravidade.

Outra forma de avaliar o nível de fraqueza muscular no paciente crítico é o uso do dinamômetro de preensão palmar. Essa avaliação pode indicar a força muscular global e servir como um teste simples para identificar a doença. ${ }^{2} \mathrm{~A}$ mão dominante é testada, com o paciente o mais sentado possível, com os cotovelos o mais próximo de $90^{\circ} .{ }^{2}$ Um valor menor que $11 \mathrm{~kg}$-força para homens e $7 \mathrm{~kg}$-força para mulheres indica a CIPNM. ${ }^{2}$ Tanto o MRC quanto a avaliação da força de preensão palmar têm concordância interobservador classificada como muito boa. ${ }^{15}$

O uso confiável da escala do MRC e da dinamometria de preensão palmar é dependente da colaboração máxima do paciente. ${ }^{16}$ Esse pré-requisito pode ser um fator impeditivo do uso mais abrangente destas avaliações. O nível de cooperação do paciente pode ser testado por cinco solicitações verbais que verificam o grau de compreensão deste (Quadro 2). ${ }^{8}$ Pode-se considerar o dia um da avaliação do MRC aquele no qual o paciente respondeu a três dessas questões duas vezes, com um intervalo de seis horas entre essas. ${ }^{8}$

As solicitações verbais feitas pedem movimentos de cabeça e face, pois essas regiões não são comumente afetadas pela CIPNM. ${ }^{4}$ Os nervos cranianos também não são acometidos, diferentemente da síndrome de Guillain-Barré e da miastenia gravis. ${ }^{17}$

A avaliação sensitiva de pacientes críticos muitas vezes é dificultada por algumas barreiras como o nível de consciência reduzido e a presença de edema. ${ }^{6}$ Quando é possível ser realizada,

\section{Quadro 2. Avaliação da cooperação do paciente ${ }^{8}$}

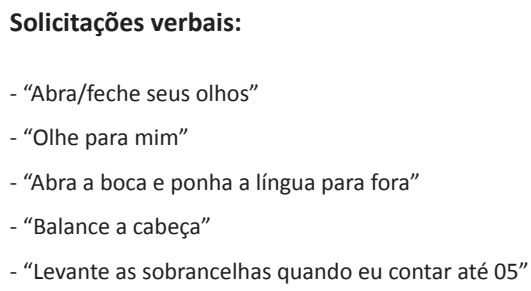


demonstra perda distal da sensação álgica, térmica e vibracional. Esse achado é mais comum na CIP que na CIM. ${ }^{7}$ Um indício precoce da presença de CIPNM é a evidência de fácies de dor ao estímulo álgico das extremidades, com pouca ou nenhuma movimentação do membro avaliado. ${ }^{6} \mathrm{O}$ exame dos reflexos profundos pode demonstrar hiporreflexia ou arreflexia; ${ }^{6}$ porém reflexos normais não excluem a CIPNM. ${ }^{17}$

Em relação ao desmame, essa doença pode gerar falhas sucessivas nesse, mesmo que esteja revertida a causa da instituição da VMI e o paciente mantenha a estabilidade cardiopulmonar. Em geral, é nesse cenário clínico em que há o diagnóstico de CIPNM, ${ }^{13}$ pois ao excluir-se outras causas de falha no desmame é confirmada a falha da bomba respiratória. Esse assunto será melhor abordado na sessão sobre a interferência da CIPNM no desmame da VMI.

Apesar de a eletroneuromiografia e a biópsia muscular serem recursos que podem mais seguramente confirmar a presença de CIP, CIM, ou CIPNM, a avaliação clínica e física de um paciente cooperativo com um quadro compatível com o de fraqueza adquirida na UTI, que foi exposto aos seus fatores de risco e com pontuação do MRC indicativa de fraqueza, dispensa esses exames invasivos, ${ }^{8}$ que requerem profissionais especializados ${ }^{17}$ e são de difícil realização na UTI. ${ }^{8}$

A recuperação da CIPNM na maioria dos pacientes é observada em algumas semanas ou até meses. ${ }^{8}$ Entretanto, nos casos em que a fraqueza é severa e/ou não há melhora nesta em uma ou duas semanas, o exame eletrofisiológico é indicado. Porém, este pode ser não diagnóstico e, nesses casos, há indicação de biópsia muscular e/ou neural, e/ou de exames eletrofisiológicos mais específicos, como a estimulação muscular direta. $^{7}$

A CIPNM é mais comum e possivelmente mais prevalente que a CIP e a CIM isoladas; ressalta-se que a fraqueza adquirida na UTI é um diagnóstico de exclusão. ${ }^{7}$

Os critérios diagnósticos para a CIPNM são: ${ }^{7}$
1. fraqueza generalizada após a instalação de doença crítica;

2. fraqueza difusa, que envolve tantos músculos proximais quanto distais, simétrica, flácida e que geralmente poupa nervos cranianos;

3. escore MRC menor que 48 pontos, visualizados em duas ocasiões distintas, separadas por 24 horas;

4. dependência da VMI;

5. outras causas de fraqueza muscular excluídas.

Para ser estabelecida a presença de CIPNM, o paciente deve apresentar, no mínimo, os critérios 1,2 e 3 , ou 4 e 5 . $^{7}$

\section{Como a CIPNM pode afetar o desmame da VMI}

Desmame da prótese ventilatória é definido como o processo de saída da VMI para a ventilação espontânea em pacientes que estavam sob esta por período superior a 24 horas. ${ }^{18} \mathrm{Co}$ mumente, a maior parte dos pacientes sob VMI internados em UTI tem esse suporte retirado em até três dias. ${ }^{19}$ Contudo, 20\% necessitam de VMI por longos períodos e seu desmame pode ocupar cerca de $40 \%$ do tempo total de prótese ventilatória. ${ }^{19}$

O motivo mais comum de dependência da VMI é a fraqueza diafragmática e dos músculos acessórios da ventilação. ${ }^{19}$ A CIPNM é uma doença que acomete não apenas os músculos apendiculares, atingindo também os ventilatórios, reduzindo sua força ${ }^{10}$ e aumentando a chance de falha do desmame. ${ }^{12}$ A presença de fraqueza muscular inspiratória provoca uma alta taxa de disparo das unidades motoras no centro respiratório, gerando esforços inefetivos decorrentes da fraqueza em si, e não pela falta de estímulo central. ${ }^{20}$ Esse fator, associado ao desequilíbrio entre a alta carga de trabalho respiratório e a reduzida força muscular inspiratória gera um baixo volume corrente (VC), provoca 
dispneia, retenção de gás carbônico e incapacidade de sustentar a ventilação espontânea, sendo necessária a reinstituição da VMI. ${ }^{20}$

A falha no desmame da prótese ventilatória ocorre quando o paciente não passou no teste de respiração espontânea (TRE) ou necessitou retornar à VMI em até 48 horas após a passagem para a ventilação espontânea. ${ }^{21}$ Assim, o sucesso no desmame ocorre quando o paciente permanece fora da VMI por mais de 48 horas. ${ }^{21}$ No entanto, é comum observar nos pacientes que estão sob VMI prolongada, principalmente os que possuem CIPNM, sinais de insuficiência respiratória aguda (IRpA) depois desse intervalo de tempo. ${ }^{10,13}$ Nesses casos específicos, é considerado sucesso no desmame apenas após 15 dias em ventilação espontânea. ${ }^{10} \mathrm{Na}$ prática, pode ser difícil manter o paciente tanto tempo internado na UTI depois do que se considera classicamente sucesso no desmame da VMI. Logo, é recomendado, à alta de um paciente com CIPNM da UTI, enfatizar para equipe da enfermaria a possibilidade de retenção de secreção traqueobrônquica (STB), hipoventilação, ou IRpA tardiamente ao sucesso no desmame. Salienta-se, então, que esse sucesso, por si só, não exclui o envolvimento dos músculos ventilatórios. ${ }^{13}$ Dessa maneira, é importante uma supervisão estrita da clínica e da função muscular respiratória desse indivíduo após saída da UTI, pois a CIPNM pode causar o retorno inesperado a essa unidade, ou mesmo o óbito. ${ }^{13}$

A CIPNM pode atrasar o início do desmame da $\mathrm{VMI}^{10}$ e ampliar o tempo deste procedimento em $\mathrm{si}^{9,10,12,14,22}$ em duas a cinco vezes, se comparado com pacientes sem CIPNM ${ }^{16}$ sendo que, quanto mais severa for a fraqueza muscular adquirida na UTI, maior o tempo em desmame da VMI. ${ }^{22}$ Essa doença é um fator preditor independente de atraso ${ }^{9}$ falha ${ }^{12}$ no desmame, podendo aumentar em mais de 15 vezes a chance de falência na extubação (EXTOT). ${ }^{12}$ A necessidade de traqueostomia (TQT) pode ser maior na fraqueza adquirida na UTI do que em pacientes sem esta. ${ }^{12}$ A presença de comorbidades, como a doença pulmonar obstrutiva crônica, pode prolongar ainda mais a liberação da VMI. ${ }^{9}$

Pacientes que sofrem reintubação orotraqueal tendem a permanecer mais tempo internados no hospital, têm maior incidência de pneumonia associada à VMI e maior taxa de mortalidade. ${ }^{23}$ Assim, a identificação precoce de pacientes com risco de VMI prolongada, ou falha de EXTOT, é crucial para avaliação de TQT precoce com o objetivo de melhorar o prognóstico do paciente e evitar as complicações da reintubação.

Garnacho-Montero e colaboradores ${ }^{12}$ verificaram em seu estudo que as três principais causas de reintubação orotraqueal na CIPNM foram a hipoxemia, o aumento do trabalho ventilatório e o prejuízo na depuração de STB. Esses são fatores que a equipe multidisciplinar deve avaliar durante a permanência do paciente fraco na UTI, uma vez que podem ser revertidos ou antecipados, como, por exemplo, com a instituição de oxigenoterapia, posicionamento adequado no leito, aplicação de ventilação não invasiva (VNI), manobras broncodesobstrutivas e aspiração traqueobrônquica.

$\mathrm{Na}$ avaliação ventilatória, faz-se importante o uso da manovacuometria, na qual se avalia a pressão inspiratória máxima (PImáx) e a pressão expiratória máxima (PEmáx), e da ventilometria, ${ }^{16}$ que determina o volume minuto (VM), o VC e frequência respiratória (FR), e o índice de respiração rápida e superficial (IRRS), para se verificar o grau de acometimento dos músculos ventilatórios pela CIPNM. Considera-se portador de fraqueza muscular inspiratória pacientes que tenham PImáx maior ou igual a - $60 \mathrm{cmH}_{2} \mathrm{O} .{ }^{19}$ Entretanto, cabe ressaltar que a PImáx preditiva para desmame deve ser mais negativa que - $30 \mathrm{cmH}_{2} \mathrm{O} \cdot{ }^{18} \mathrm{Um}$ sinal significativo de fraqueza muscular respiratória é a PImáx progressivamente mais baixa. Valores indicativos na ventilometria de disfunção muscular ventilatória são: VM maior que 10 l/min; VC menor que $250 \mathrm{ml}$ e capacidade vital (CV) menor que $11 .{ }^{19}$

Uma medida grosseira da CV em pacientes respirando espontaneamente e sem via aérea ar- 
tificial pode ser realizada pedindo-se ao paciente para respirar profundamente e contar até $20 \mathrm{em}$ voz alta, com um único fôlego, sem pausas: caso o paciente seja inapto para a tarefa, considera-se que este possui CV marcadamente baixa, entre 15 e $18 \mathrm{ml} / \mathrm{kg} ;{ }^{13}$ nesses valores, a VMI ou a VNI é indicada. ${ }^{16}$ Pacientes que apresentam $\mathrm{CV}$ entre 20 e $30 \mathrm{ml} / \mathrm{kg}$ têm indicação de fisioterapia torácica intensiva. ${ }^{13}$ Valores normais da CV estão entre 65 e $75 \mathrm{ml} / \mathrm{kg} .{ }^{16}$

Um grupo de investigadores observou associação significativa entre a fraqueza periférica e a ventilatória, e demonstrou que quanto menor a pontuação na escala do MRC menor era a PImáx, PEmáx e $\mathrm{CV} \cdot{ }^{10} \mathrm{O}$ mesmo grupo evidenciou, desse modo, que a fraqueza periférica pode refletir fraqueza respiratória. De Jonghe e colaboradores ${ }^{10}$ verificaram que ambas, PImáx e PEmáx, reduzidas ao despertar eram fatores independentes de atraso da EXTOT: indivíduos com PImáx baixa tinham oito vezes mais chance de permanecer em VMI por mais de uma semana após o despertar, comparados aos que tinham PImáx alta; aqueles que apresentavam PEmáx baixa, tinham essa chance aumentada em quatro vezes, comparados aos que tinham PEmáx alta. Logo, de acordo com os autores, essas alterações da força indicaram associação com uma importante dependência da VMI.

A equipe da UTI, ao diagnosticar um paciente como portador de CIPNM, deve correlacionar a fraqueza periférica com a fraqueza dos músculos da respiração. O momento do início do desmame ou seu seguimento deve ter incluído como rotina técnica a avaliação de variáveis ventilatórias e do escore do MRC, principalmente dos membros superiores. Em um estudo com doentes sob VMI prolongada e desmame difícil, Martin e colaboradores ${ }^{24}$ verificaram que a força de membros superiores se correlacionou melhor com a aptidão de ventilar espontaneamente do que o IRRS.

No nosso serviço de fisioterapia na UTI Geral do Hospital Universitário Pedro Ernesto, é feita a avaliação de rotina do escore do MRC, da dinamometria de preensão palmar e das variáveis ventilatórias, sob protocolo, dos pacientes em VMI prolongada e/ou com desmame difícil, com o objetivo de detecção precoce da fraqueza muscular periférica e respiratória. Caso o paciente tenha fraqueza muscular, as avaliações são mantidas para acompanhar a evolução e para reajuste das condutas realizadas pela equipe. O uso das equações preditivas de PImáx e PEmáx ${ }^{25}$ (Quadro 3) também podem ser úteis para fornecer uma avaliação individualizada do paciente.

Diferentemente das outras doenças neuromusculares, a CIPNM surge após a IRpA. ${ }^{17}$ Durante o desmame da VMI ou mesmo após 48 horas deste, a IRpA na CIPNM tende a ser insidiosa e de difícil identificação, apresenta gasometria com moderada hipoxemia, acompanhada com hipocapnia. ${ }^{16}$ Com a evolução do quadro, o paciente pode apresentar acidose respiratória. A radiografia de tórax pode ser normal. Ao exame físico, o paciente pode apresentar respiração curta, taquipneia, dispneia, uso de músculos acessórios da ventilação, sudorese e taquicardia, podendo haver tosse ineficaz e acúmulo de STB. ${ }^{16}$ A ausência de sinais claros e precoces de IRpA pode retardar o tratamento adequado, com intervenção tardia da equipe e piora do prognóstico. ${ }^{16}$ Sugere-se que nesse grupo de pacientes sinais discretos de IRpA, como pode ser a dispneia ao falar ou ao engolir, ${ }^{13}$ sejam valorizados a fim de se realizar intervenção mais precoce.

Quadro 3. Equações preditivas de pressões inspiratórias e expiratórias máximas ${ }^{25}$

\begin{tabular}{|c|}
\hline Pressão inspiratória máxima \\
\hline - Sexo masculino: $-0,80 \times$ (idade) $+155,3$ \\
- Sexo feminino: $-0,49 \times$ (idade ) $+110,4$ \\
\hline Pressão expiratória máxima \\
- Sexo masculino: $-0,81 \times$ (idade ) $+165,3$ \\
- Sexo feminino: $-0,61 \times$ (idade ) $+115,6$ \\
\hline
\end{tabular}




\section{Alterações neuromusculares na CIPNM}

A patofisiologia das anormalidades neuro-musculares da CIPNM é muito complexa e possui muitos mecanismos propostos, sendo que a maioria ainda não foi comprovada ou completamente compreendida. ${ }^{5,17}$ Uma das teorias é que essa doença é apenas mais um tipo de falência orgânica que é vista no doente crítico. ${ }^{17}$

Pacientes internados na UTI que foram expostos aos fatores de risco para desenvolver CIPNM mostram anormalidades eletrofisiológicas em uma média de seis dias de internação. ${ }^{26} \mathrm{O}$ principal e primeiro evento que causa a fraqueza muscular é a inexcitabilidade da sarcolema, ${ }^{27}$ que permanece hiperpolarizada pela inativação dos seus canais de sódio e por uma diminuição pela metade da densidade desses, afetando a geração do potencial de ação para a contração muscular. ${ }^{4}$ A perda de massa muscular ocorre depois dessas alterações eletrofisiológicas. ${ }^{27}$

A sepse pode causar redução na área de secção transversa de fibras tipo $\mathrm{I}^{28}$ e tipo $\mathrm{II},{ }^{29} \mathrm{da}$ força muscular e da endurance $e^{28,29}$ e aumentar a constante de tempo para contração e relaxamento. ${ }^{28,29} \mathrm{Em}$ pacientes críticos, pode-se ter perda de 1,5 kg de massa muscular por dia. ${ }^{27}$ Logo, durante a ectoscopia, pode-se encontrar redução no trofismo muscular nesses pacientes. ${ }^{13}$

Histologicamente, a CIM demonstra perda seletiva de miosina, que é considerada um sinal patognomônico da doença, ${ }^{7}$ havendo atrofia das fibras musculares tipo II e, ocasionalmente, atrofia de fibras tipo I. ${ }^{4}$ Nas biópsias de nervos na CIP, é observada perda axonal primária nos segmentos distais neurais quando comparados com os proximais, sem evidência inflamatória ou de desmielinização. ${ }^{14} \mathrm{Na}$ CIP pode haver, ainda, atrofia por denervação, assim como anormalidades citoarquiteturais das fibras tipo I e II. ${ }^{14}$ Pode-se ter também miosinólise e mionecrose, ${ }^{8}$ além de miopatia associada. ${ }^{7}$

A função mitocondrial durante a doença crítica está prejudicada e há menor biossíntese de adenosina trifosfato, geração e uso de energia, o que pode estar relacionado com a disfunção celular e orgânica. Assim, músculos e nervos, que são tecidos excitáveis, podem ser lesados por uma combinação de hipóxia isquêmica e citopática. $^{5}$

O choque séptico é um fator independente de fraqueza muscular respiratória, ${ }^{10}$ causando redução da capacidade do diafragma de gerar força, do seu limiar de fadiga, do fluxo sanguíneo e de sua massa muscular, assim como aumento na sua proteólise. ${ }^{30} \mathrm{Na} \mathrm{CIP}$, comumente encontra-se neuropatia frênica e denervação diafragmática. ${ }^{31}$

Os músculos cervicais, torácicos e abdominais também podem ser atingidos pela CIPNM. ${ }^{14}$ Isso pode acometer a capacidade do paciente de assumir posturas antigravitacionais. O comprometimento da musculatura abdominal pode causar prejuízo na relação antagônicosinérgica entre esses músculos e o diafragma, prejudicando o componente aposicional diafragmático e, assim, obstar a capacidade de modificação dos diâmetros torácicos e geração de pressão inspiratória, reduzindo a eficiência ventilatória. ${ }^{32}$ Consequentemente, pode haver prejuízo na eficácia da tosse e na capacidade de vencer resistência aumentada das vias aéreas ${ }^{32}$ por reduzida PEmáx. ${ }^{10}$ Tais alterações também aumentam a chance de reintubação, principalmente em casos de hipersecretividade. ${ }^{33}$

Especificamente, a redução das fibras tipo II pode prejudicar o aumento da FR, assim como o decréscimo das fibras tipo I podem reduzir a endurance ventilatória. As alterações neuromusculares citadas podem gerar IRpA hipercápnica, pois podem provocar inabilidade dos músculos ventilatórios de responderem adequadamente ao aumento da demanda orgânica. ${ }^{32}$

\section{Prevenção e terapêuticas específicas para CIPNM}

A recuperação do paciente portador de CIPNM depende de inúmeros fatores, incluindo a idade do indivíduo, a doença de base, comorbidades e o nível de intensidade da reabilitação. ${ }^{16}$ 
Há escassez de evidências científicas que comprovem a maneira de prevenir ou tratar a CIPNM. No entanto, parece que a identificação dos fatores de risco precocemente pode ser útil para tentativa de ajuste da terapêutica adequada, verificando a possibilidade de diminuir a exposição dos pacientes a esses. ${ }^{6}$

$\mathrm{O}$ controle glicêmico adequado através da infusão de insulina demonstrou reduzir a incidência de CIPNM. ${ }^{6}$ A utilização de medicamentos que potencialmente podem causar CIPNM, como os corticosteroides e os bloqueadores neuromusculares (BNM), deve ser revista com cautela, ${ }^{6}$ apesar dos estudos que associaram causa e efeito serem escassos. ${ }^{3}$

O uso de protocolos de interrupção diária da sedação associado à reabilitação precoce tem demonstrado diminuição no tempo de VMI e no período de permanência na UTI. ${ }^{5}$ Somado a isso, a retirada da sedação pode favorecer o despertar do paciente, possibilitando mais precocemente o exame neuromotor e a detecção da fraqueza muscular adquirida na UTI. Favorece também a minimização da imobilidade decorrente da sedação, assim como proporciona a reabilitação mais precoce. ${ }^{6}$

A sedação deve ser interrompida sempre que possível e o paciente submetido ao TRE, sendo o TRE em peça $\mathrm{T}$ por 30 minutos o principal teste diagnóstico para se avaliar a possibilidade de EXTOT. ${ }^{21}$ Associado a outros fatores, a avaliação da EXTOT é feita pela verificação de medidas ventilatórias (exemplo: PImáx, PEmáx e IRRS) e TRE diários. ${ }^{21} \mathrm{~A}$ instituição de protocolos específicos para desmame reduz a sua duração e diminui as complicações associadas à VMI prolongada. ${ }^{21}$ Apesar dessas recomendações serem para pacientes intubados, é possível que pacientes traqueostomizados também sejam beneficiados por elas.

Em alguns casos, a TQT precoce deve ser considerada, ${ }^{32}$ principalmente quando há a expectativa de permanência do paciente em VMI por mais de 14 dias. ${ }^{18}$ Este procedimento reduz a incidência de pneumonia associada à VMI e de sepse, promove um menor tempo na
UTI, menor tempo de desmame da VMI e uma menor mortalidade. ${ }^{18}$

Teoricamente, a nutrição e o equilíbrio eletrolítico adequados nessa doença são benéficos para que o paciente tenha um suprimento energético suficiente para suas demandas orgânicas e substratos que possibilitem a contração muscular. ${ }^{6} \mathrm{O}$ suporte nutricional deve incluir aminoácidos específicos, como a arginina e a glutamina, sendo esse último considerado um estimulante à síntese proteica e inibidor da proteólise. ${ }^{17}$

A cinesioterapia parece ser capaz de reverter a fraqueza muscular do paciente crítico, promover retorno mais rápido à função e reduzir o tempo de desmame e de internação, ${ }^{34}$ devendo ser iniciada o mais precocemente possível. É uma intervenção segura e eficaz mesmo durante a fase aguda da doença crítica. ${ }^{34} \mathrm{~A}$ mobilização passiva $^{37} \mathrm{e}$ a atividade muscular possuem função anti-inflamatória, ${ }^{38}$ que pode ser potencialmente benéfica para esses pacientes. ${ }^{38}$

Martin e colaboradores, ${ }^{24}$ em um estudo com pacientes em desmame difícil que estavam sob reabilitação intensiva, evidenciaram que o ganho de um ponto no teste muscular manual dos membros superiores correspondia a, aproximadamente, sete dias a menos em desmame da VMI. A hipótese dos autores é que isso ocorreu devido ao aumento da força do músculo peitoral maior, por ser um importante acessório da ventilação, tendo tanto funções inspiratórias quanto expiratórias.

Um estudo demonstrou que a reabilitação precoce associada à retirada diária da sedação foi capaz de melhorar a independência funcional pós-alta hospitalar, reduzir o tempo de VMI, a incidência de delirium e de CIPNM, quando comparados com pacientes que tiveram início tardio da reabilitação. ${ }^{35}$ Um grupo que reabilitou pacientes com CIPNM ainda na UTI demonstrou que esses doentes apresentaram aumento da força muscular e da independência funcional ao final do estudo. ${ }^{36}$

Outra abordagem cinesioterapêutica que pode ser usada na fraqueza muscular adquirida 
na UTI, mais especificamente na fraqueza inspiratória, é o treinamento muscular inspiratório (TMI). O TMI aumenta a força muscular e a endurance inspiratória, ${ }^{19}$ sendo capaz de favorecer e possibilitar o desmame da VMI de pacientes com desmame difícil. ${ }^{39}$ Pode-se combinar o TMI através do uso de resistor linear com o desmame gradual em peça $\mathrm{T}^{21}$ Ressalta-se que os músculos expiratórios também devem ser reabilitados. Sendo a CIPNM uma doença que acomete tanto os músculos periféricos quanto os respiratórios, ${ }^{10}$ parece ser útil o uso da cinesioterapia associada ao fortalecimento muscular respiratório para tentar favorecer um melhor desfecho desses pacientes; porém, são necessários mais estudos controlados e randomizados para comprovação desses resultados clínicos.

Em resumo, aconselha-se, com objetivo profilático e terapêutico para a CIPNM, o controle da hiperglicemia, ${ }^{6}$ a restrição a medicamentos que potencialmente possam gerar a fraqueza adquirida na UTI, ${ }^{6}$ o uso de protocolo de despertar diário, ${ }^{5}$ assim como os de desmame da $\mathrm{VMI},{ }^{21}$ a nutrição, a manutenção do equilíbrio eletrolítico adequados ${ }^{6} \mathrm{e}$ a fisioterapia precoce. ${ }^{35}$

\section{Conclusão}

Apesar da fisiopatologia completa da CIPNM ainda ser desconhecida, suas lesões neuromusculares são bem-descritas na literatura e culminam na redução da funcionalidade do paciente crítico e na dificuldade deste em sair da prótese ventilatória, pois acometem tanto os nervos e músculos dos membros quanto os respiratórios.

A avaliação física desses pacientes deve ser criteriosa e realizada o mais rapidamente possível, sendo a aplicação da escala do MRC um meio eficaz, confiável e fácil de ser realizado à beira do leito para a identificação da doença, assim como parece ser o uso do dinamômetro de preensão palmar. As medidas ventilatórias são úteis para identificar a repercussão da CIPNM nos músculos respiratórios. As avaliações periódicas visam também verificar a efetividade do tratamento.
Ainda não existem terapêuticas específicas para tratar a fraqueza adquirida na UTI. Entretanto, evitar expor o paciente aos fatores de risco relacionados com esta, ou ao menos controlá-los, parece ser um meio racional de prevenção ou tratamento dessa doença. Associado a isso, o uso de protocolos de despertar diário e de desmame, assim como a nutrição adequada e a cinesioterapia desde a fase aguda, pode $(\mathrm{m})$ promover um desfecho mais benéfico para o paciente portador de CIPNM.

A equipe multidisciplinar deve estar atenta à presença dessa afecção, com a finalidade de agir precocemente, visando reduzir seus efeitos deletérios.

\section{Agradecimentos}

Gostaríamos de agradecer ao Dr. Sérgio da Cunha e à Enf. ${ }^{a}$ Luana Almeida pelo o convite para fazermos a presente revisão de literatura.

\section{Referências}

1. Visser LH. Critical illness polyneuropathy and myopathy: clinical features, risk factors and prognosis. Eur J Neurol. 2006;13:1203-12.

2. Naeem A, O'Brien J, Hoffmann S, Philips G, Garland A, Finley JC, Almoosa K, et al. Acquired weakness, handgrip strength, and mortality in critically ill patients. Am J Respir Crit Care Med. 2008 Aug 1;178(3):261-8. http:// dx.doi.org/10.1164/rccm.200712-1829OC

3. Stevens RD, Dowdy DW, Michaels RK, Mendez-Tellez PA, Pronovost PJ, Needham DM. Neuromuscular dysfunction acquired in critical illness: a systematic review. Intensive Care Med. 2007;33 (11):1876-91.

4. Khan J, Harrison TB, Rich MM. Mechanisms of Neuromuscular Dysfunction in Critical Illness. Crit Care Clin. 2008;24(1):1-11. http:// dx.doi.org/10.1016/j.ccc.2007.10.004

5. Latronico N, Bolton CF. Critical illness polyneuropathy and myopathy: a major cause of muscle weakness and paralysis. Lancet Neurol. 2011 Oct;10(10):931-41. http:// dx.doi.org/10.1016/S1474-4422(11)70178-8

6. Schweickert WD, Hall J. ICU-Acquired Weakness. Chest 2007;131:1541-49.

7. Stevens RD, Marshall SA, Cornblath DR, Hoke A, Needham DM, de Jonghe B, et al. A framework for diagnosing and 
classifying intensive care unit-acquired weakness. Crit Care Med. 2009 Oct;37(10 Suppl):S299-308. http://dx.doi.org/10.1097/ CCM.0b013e3181b6ef67

8. De Jonghe B, Sharshar T, Lefaucheur J-P, Authier FJ, Durand-Zaleski I, Boussarsar M, et al. Paresis acquired in the intensive care unit: a prospective multicenter study. JAMA. 2002;288:2859-67.

9. De Jonghe B, Bastuji-Garin S, Sharshar T, Outin H, Brochard L. Does ICUAcquired Paresis lengthen weaning from mechanical ventilation? Intensive Care Med. 2004;30:1117-21.

10. De Jonghe B, Bastuji-Garin S, Durand M-C, Malissin I, Rodrigues P, Cerf C, et al. Respiratory weakness is associated with limb weakness and delayed weaning in critical illness. Crit Care Med. 2007;35:2007-15.

11. Van Der Schaaf M, Beelen A, De Vos Rien. Functional Outcome in Patients with Critical Illness Polyneuropathy. Disabil Rehabil. 2004; 26:1189-97.

12. Garnacho-Montero J, Amaya Villar R, GarciaGarmendia JL, Madrazo-Osuna J, Ortiz-Leyba C. Effect of critical illness polyneuropathy on the withdrawl from mechanical ventilation and the length of stay in septic patients. Crit Care Med. 2005;33:349-53.

13. Latronico N, Guarneri B, Alongi S, Bussi G, Candiani A. Acute Neuromuscular Respiratory Failure After ICU Discharge. Intensive Care Med. 1999;25:1302-6.

14. Bolton CF, Gilbert JJ, Hahn AF, Sibbald WJ. Polyneuropathy in Critical Ill Patients. J Neurol Neurosurg Psychiatry. 1984;47:1223-31.

15. Hermans G, Clerckx B, Vanhullebusch T, Segers J, Vanpee G, Robbeets C, et al. Interobserver agreement of Medical Research Council sum-score and handgrip strength in the intensive care unit. Muscle Nerve. 2012 Jan;45(1):18-25.

16. Latronico N, Rasulo FA. Presentation and management of ICU myopathy and neuropathy. Curr Opin Crit Care. 2010 Apr;16(2):123-7.

17. Confer J, Wolcott J, Hayes R. Critical illness polyneuromyopathy. Am J Health Syst Pharm. 2012 Jul 15;69(14):1199-205.

18. Goldwasser R, Farias A, Freitas EE, Saddy F, Amado V, Okamoto VN. Desmame e interrupção da ventilação mecânica. Rev Bras Ter Intensiva. 2007;19 (3):384-92.

19. Veloso CA, Figueiredo LC. Treinamento Muscular. In: Sarmento GJV, Veja JM, Lopes NS. Fisioterapia em UTI. Rio de Janeiro: Atheneu; 2010.
20. Purro A, Appendini L, De Gaetano A, Gudjonsdottir M, Donner CF, Rossi A. Physiologic determinants of ventilator dependence in long-term mechanically ventilated patients. Am J Respir Crit Care Med. 2000 Apr;161(4 Pt 1):1115-23.

21. Boles J-M, Blon J, Connors A, Herridge M, Marsh B, Melote C, et al. Weaning from mechanical ventilation task force. Statement of the sixth international consensus conference on intensive care medicine. Eur Respir J. 2007;29:1033-56. http://dx.doi. org/10.1183/09031936.00010206

22. Maher J, Rutledge F, Remtulla H, Parkes A, Bernardi L, Bolton CF. Neuromuscular disorders associated with failure to wean from the ventilator. Intensive Care Med. 1995;21:737-43.

23. Seymour CW, Martinez A, Christie JD, Fuchs BD. The outcomes of extubation failure in a community hospital intensive care unit: a cohort study. Crit Care. 2004;R332-27.

24. Martin UJ, Hincapie L, Nimchuk M, Gaughan J, Criner GJ. Impact of whole-body rehabilitation in patients receiving chronic mechanical ventilation. Crit Care Med. 2005;33:2259-65.

25. Kunikoshita LN, Silva YP, Silva TLP, et al. Efeito de três programas de fisioterapia respiratória (PFR) em portadores de DPOC. Revista Brasileira de Fisioterapia. 2006;10(4):449-55.

26. Guarneri B, Bertolini G, Latronico N. Long-term outcome in patients withcritical illness myopathy or neuropathy: the Italian multicentre CRIMYNE study. J Neurol Neurosurg Psychiatry. 2008 Jul;79(7):838-41.

27. Wagenmakers AJM. Muscle Function in Critically Ill Patients. Clin Nutr. 2001;20(5):451-4.

28. Rannou F, Pennec JP, Rossignol B, Morel J, Dorange G, Arvieux C, et al. Effects of chronic sepsis on rat motor units: experimental study of critical illness polyneuromyopathy. Exp Neurol. 2007:741-7.

29. Rossignol B, Gueret G, Pennec JP, Morel J, Rannou F, Giroux-Metges MA, et al. Effects of chronic sepsis on contractile properties of fast twitch muscle in an experimental model of critical illness neuromyopathy in the rat. Crit Care Med. 2008 Jun;36(6):1855-63. http:// dx.doi.org/10.1097/CCM.0b013e318176106b

30. Lanone S, Taillé C, Boczkowski J, Aubier M. Diaphragmatic fatigue during sepsis and septic shock. In: Pinsky MR, Brochard L, Mancebo J. Applied Physiology in Intensive Care Medicine. Berlin: Springer-Verlag Heidelberg; 2006.

31. Zifko UA, Zipko HT, Bolton CF. Clinical and 
electrophysiological findings in critical illness polyneuropathy. J Neurol Sci. 1998;159(2):186-93.

32. Zamora VEC, Joia IAT, Silva KM. Impacto da polineuromiopatia do paciente crítico no desmame da ventilação mecânica. Fisioterapia Brasil. 2010;11(1):54-60.

33. Khamiees M, Raju P, DeGirolamo A, Amoateng-Adjepong Y, Manthous CA. Predictors of extubation outcome in patients who have successfully completed a spontaneous breathing trial. Chest. 2001;120:1262-70.

34. Silva APP, Maynard K, Cruz MR. Efeitos da fisioterapia motora em pacientes críticos: revisão de literatura. Rev Bras Ter Intensiva. 2010;22(1):85-91.

35. Schweickert WD, Pohlman MC, Pohlman AS, Nigos C, Pawlik AJ, Esbrook CL, et al. Early physical and occupational therapy in mechanically ventilated, critically ill patients: a randomised controlled trial. Lancet. 2009 May 30;373(9678):1874-82. http://dx.doi. org/10.1016/S0140-6736(09)60658-9
36. Nordon-Craft A, Schenkman M, Ridgeway $\mathrm{K}$, Benson A, Moss M. Physical therapy management and patient outcomes following ICU-acquired weakness: a case series. J Neurol Phys Ther. 2011 Sep;35(3):133-40. http://dx.doi.org/10.1097/ NPT.0b013e3182275905

37. Winkelman C, Higgins PA, Chen YJ, Levine AD. Cytokines in chronically critically ill patients after activity and rest. Biol Res Nurs. 2007 Apr;8(4):261-71.

38. Needham DM. Mobilizing patients in the intensive care unit: improving neuromuscular weakness and physical function. JAMA. 2008 Oct 8;300(14):1685-90. http://dx.doi. org/10.1001/jama.300.14.1685

39. Martin AD, Smith BK, Davenport PD, Harman E, Gonzalez-Rothi RJ, Baz M, et al. Inspiratory muscle strength training improves weaning outcome in failure to wean patients: a randomized trial. Crit Care 2011;15(2):R84. http://dx.doi.org/10.1186/ cc10081. 


\title{
A psicologia médica no centro de tratamento intensivo do Hospital Universitário Pedro Ernesto
}

\author{
Psychology in Pedro Ernesto University Hospital intensive care unit
}

Janete A. Araújo*

Elizabeth M. P. Leitão

\section{Resumo}

A unidade de tratamento intensivo (UTI) é um ambiente de cuidados da saúde com potencial de gerar estados emocionais que podem interferir na evolução do paciente. Os cuidados são oferecidos, através de tratamentos complexos, aos pacientes em graves condições médicas, a fim de garantir a sua sobrevivência e a melhoria do seu estado geral. Além da debilidade física, os pacientes são, ainda, submetidos a situações de estresse importante. Frequentemente mantidos sedados durante o período de recuperação da consciência, são expostos a inúmeros fatores extremamente difíceis do ponto de vista emocional, acarretando síndromes psiquiátricas bastante prevalentes e atenção especializada. A hospitalização de um membro da família desorganiza a dinâmica familiar, ficando ainda mais complexa se a internação ocorre na UTI, pois esta, por si só, simboliza o risco iminente de morte. Os problemas derivados das características ambientais da unidade, cuidado ao paciente, necessidade de uma sólida base de conhecimentos e dificuldades de comunicação interpessoal aumentam a sobrecarga emocional na equipe de saúde. Provocam ansiedade, depressão e o aparecimento de mecanismos de defesa para lidar com as situações de conflito. A inserção do psicólogo neste ambiente objetiva identificar e atuar sobre aspectos que possam interferir na adaptação do paciente ao período de hospitalização e na sua recuperação. A equipe de psicologia médica da UTI geral do Hospital Universitário Pedro Ernesto visa identificar e apoiar os aspectos emocionais dos pacientes e familiares, contribuir na adequada evolução desses indivíduos, bem como promover uma boa comunicação entre as pessoas envolvidas no processo, visando melhorar as relações e o bem-estar de todos.

Descritores: Unidades de terapia intensiva; $\mathrm{Pa}$ cientes; Comunicação; Equipe de assistência ao paciente; Psicologia médica. 


\section{Abstract}

The intensive care unit (ICU) is an environment for health care able to generate emotional situations that can intervene in the patient evolution. Care is offered through complex treatments to patients that present serious medical situation, in order to assure the survival and to improve better health conditions. Besides their physical weakness patients are submitted to important stress. Some are often maintained in a state of sedation and, during the period of progressive recovery of consciousness, they are exposed to various extremely difficult factors from an emotional point of view, causing psychiatric syndromes quite prevalent and requiring specialized attention. The hospitalization of a family member disrupts the family dynamic, addittionally, if hospitalization occurs in the ICU, the situation is even more complex because the ICU itself symbolizes the imminent risk of death. The problems that come from the environmental characteristics of the unit, the patient care, the need for a solid basis of knowledge and the difficulties on interpersonal communication increase the emotional charge on the healthcare team. This causes anxiety responses, depression and the development of defense mechanisms to deal with conflict situations. The introduction of the psychologist in this environment aims to identify and act on aspects that can intervene on the patient adaptation in the hospitalization period and his recuperation. Medical Psychology Service of General ICU of the Pedro Ernesto University Hospital aims at identifying and supporting emotional aspects of patients and families in order to contribute to a proper evolution of these individuals, as well as to promote a good communication between people involved in the process, in order to improve the better relations and the comfort of everybody.

Keywords: Intensive care units; Patients; Communication; Patient care team; Psychology, medical.

\section{Introdução}

A inserção da psicologia nos hospitais brasileiros aconteceu em um período recente da história do país, de acordo com Angerami-Camon, ${ }^{1}$ no início dos anos 1950. No centro de tratamento intensivo (CTI) geral do Hospital Universitário Pedro Ernesto (HUPE), desde a década de 1990 a psicologia médica tem feito parte da equipe multiprofissional, buscando dar suporte psicológico aos pacientes e seus familiares, facilitando o enfrentamento dos momentos de crise e das adaptações em relação ao processo de internação.

Quando o paciente é admitido numa unidade fechada fica exposto a diversos agentes estressores: confinamento, restrição ao leito, cirurgias, uso de aparelhos, ruídos e iluminação constantes, realização frequente de exames, afastamento do trabalho, dos amigos, dificuldade em conciliar o sono e mudanças alimentares repentinas, para citar apenas alguns. Esses agentes podem ocasionar reações emocionais em variados níveis, como ansiedade, medo, conflitos, insegurança, irritabilidade, dentre outras comumente relacionadas ao contexto da internação. ${ }^{2}$

$\mathrm{Na}$ unidade de terapia intensiva (UTI), a rotina de trabalho mais acelerada, o clima constante de apreensão e as situações de morte iminente tornam ainda mais possíveis as interferências emocionais da hospitalização no paciente e em seus familiares.

A preocupação generalizada dos profissionais da área de saúde em prestar uma assistência mais humanizada reforça a necessidade de manejar de forma mais adequada os aspectos emocionais do adoecer. Dessa forma, os profissionais de saúde estão sendo estimulados a se aperfeiçoarem e a complementarem seus conhecimentos para que possam atender aos pacientes a partir uma visão biopsicossocial, não mais apenas biológica. ${ }^{3}$ Trata-se de uma mudança difícil, que necessita da ajuda do psicólogo.

O objetivo deste artigo é descrever a atuação dos profissionais de psicologia no CTI geral do HUPE, citando os procedimentos e recursos uti- 
lizados, nas intervenções com todos os sujeitos envolvidos no processo de internação: pacientes, familiares e equipe de saúde.

\section{Unidade de terapia intensiva}

No final da década de 1940, início da de 1950, uma grande epidemia de poliomielite assolou a Europa e a América do Norte. Com o objetivo de proporcionar a necessária assistência ventilatória aos pacientes mais graves, foram criadas, nos Estados Unidos, as unidades de assistência ventilatória que dariam origem posteriormente à UTI ou CTI.

A UTI, destinada ao atendimento de pacientes em risco de vida, com potencial de recuperação, surgiu, assim, nos Estados Unidos, na década de 1950, época em que foram desenvolvidos os primeiros respiradores artificiais. ${ }^{4}$

No Brasil, esse tipo de serviço surgiu a partir da década de 1960, em hospitais de grande porte no Sul e Sudeste do país. No HUPE, o CTI geral foi inaugurado em abril de 1974.

A UTI foi criada e permanece até hoje com o objetivo de concentrar três componentes críticos: os doentes mais graves com possibilidade de recuperação; o equipamento técnico mais caro e sofisticado; e a equipe com conhecimento e experiência para cuidar desses pacientes e lidar com essa aparelhagem específica. ${ }^{5}$

Nos primeiros anos de sua existência, a aparelhagem e os medicamentos para suporte de vida eram precários, sendo as taxas de mortalidade muito elevadas. Mais tarde, com o avanço tecnológico caracterizado, sobretudo, pelos respiradores e monitores mais modernos e drogas cada vez mais poderosas, a prática da terapia intensiva tornou-se mais eficaz, com acentuado aumento nas taxas de sobrevivência dos pacientes. ${ }^{6}$

Nas décadas de 1980 e 1990, começou a surgir a preocupação com a humanização da prática médica e este conceito passou a ter importância em várias UTIs, inicialmente através da colocação de símbolos externos (abertura de janelas com vista para o exterior, colocação de relógios e calendários, meios de lazer como rádios e televisões etc.) para diminuir o desconforto dos pacientes e, logo a seguir, com um movimento que visava conscientizar os profissionais que ali atuavam a respeito da necessidade de mudanças de atitude na relação com os pacientes e familiares. Talvez a melhora das condições técnicas, com a diminuição do estresse da equipe, tenha sido um importante fator para possibilitar este movimento, ainda em andamento, de humanização das UTIs.

Se por um lado a tecnologia tem contribuído para os avanços da medicina, por outro, de certo modo, tem restringido o contato humano entre a equipe de saúde, os pacientes e familiares.

Nos últimos anos, alguns aspectos vêm contribuindo para mudanças no ambiente das UTIs. Essas mudanças estão relacionadas com a evolução conceitual do processo saúde-doença que implica a interlocução de novos saberes para sua compreensão e abordagem. ${ }^{7}$ Desse modo, hoje se observam equipes mistas, compostas por diversos profissionais da área da saúde, com conhecimentos e habilidades diferenciadas, desenvolvendo um trabalho multidisciplinar.

A equipe multidisciplinar é composta por médicos intensivistas, enfermeiros, fisioterapeutas, técnicos de enfermagem, nutricionistas, assistentes sociais, psicólogos e fonoaudiólogos que possuem treinamento específico e diferenciado voltado para o trabalho com pacientes críticos.

De acordo com Ayres, ${ }^{7}$ a UTI é um lugar de cuidados, onde os atores (profissionais de saúde, pacientes e familiares) precisam estabelecer um padrão de comunicação em que todos compreendam objetivamente o que está sendo dito. As habilidades de comunicação precisam ser eficazes para que se produza alta qualidade de cuidados para o paciente e suas famílias.

As características intrínsecas à UTI, como a rotina de trabalho acentuada, o clima de constante apreensão e as situações de morte iminente, acabam por exacerbar o estado de estresse e tensão, no qual, tanto o paciente quanto a equipe, vivem 24 horas por dia. Esses aspectos, somados à dimensão individual do sofrimento 
da pessoa internada, tais como a dor, o medo, o desconhecido, o isolamento do mundo, desencadeiam vários e fortes fatores psicológicos ${ }^{8}$ que interatuam muitas vezes na enfermidade que o sujeito possui.

\section{A psicologia na UTI}

Ao longo do desenvolvimento da psicologia nota-se que, apesar de um tradicional panorama clínico, houve uma série de mudanças tanto com relação às competências dos psicólogos como à própria visão dos sujeitos dos cuidados psicológicos. ${ }^{9}$ Por volta da década de 1970 iniciaram-se demandas por trabalhos psicológicos sob uma nova perspectiva, que abrange uma clientela diferenciada, um local distinto e, principalmente, a necessidade de se considerar o contexto no qual os sujeitos estão inseridos.

Tudo isto conduziu a uma mudança na concepção da prática, resultando na ampliação do campo. Dentro deste movimento, o que mais se destacou foi o relativo à área da saúde.

Em se tratando da atuação do psicólogo em uma UTI, seu objetivo é dar suporte psicológico, através de uma escuta diferenciada, ao paciente, aos familiares e a toda a equipe de saúde que está envolvida dentro do processo de adoecimento. Possibilita assim a exteriorização e o enfrentamento do sofrimento, da dor e de questões emergentes, facilitando o esclarecimento de dúvidas e de "fantasias" que provocam desconforto.

Ismael ${ }^{10}$ aponta a complexidade do processo vivenciado por estes sujeitos, pois a UTI é vista por algumas pessoas como "local para morrer". Surgem então sentimentos relacionados à desagregação e ao desamparo; o paciente, distante de seus familiares, em um ambiente impessoal, com um aparato tecnológico desconhecido, poderá reagir emocionalmente de forma negativa.

No CTI geral do HUPE, desde a década de 1990, a psicologia médica tem feito parte da equipe multiprofissional, buscando dar suporte psicológico aos pacientes e seus familiares, facilitar o enfrentamento dos momentos de crise e das adaptações em relação ao processo de internação. Estando presente junto ao mé- dico no momento em que são transmitidas aos familiares notícias sobre o estado clínico do paciente, visa mediar a comunicação e dar apoio às duas partes.

Uma característica ímpar do CTI geral do HUPE é a autorização para a visita de crianças aos familiares internados com a permissão dos responsáveis, após avaliação da equipe e desde que acompanhadas da psicóloga.

É função também da psicologia médica facilitar a relação interpessoal entre a equipe multiprofissional, os pacientes e os seus familiares, bem como fornecer espaço para atendê-los sempre que necessário.

\section{O paciente}

Simonetti ${ }^{11}$ afirma que, diante da doença, o ser humano manifesta subjetividades: sentimentos, desejos, pensamentos e comportamentos, fantasias e lembranças, crenças, sonhos, conflitos e sua maneira própria de adoecer.

Esses aspectos podem aparecer como causa da doença, como desencadeador do processo patogênico, como agravante do quadro clínico, como fator de manutenção do adoecimento ou, ainda, como consequência deste. Nesse sentido, o objetivo da psicologia é a elaboração simbólica do adoecimento, ou seja, ajudar o paciente a atravessar a experiência do adoecimento através de sua subjetividade.

O sofrimento físico e psíquico do paciente precisa ser entendido como uma coisa única, pois os dois aspectos interferem um no outro. Através do trabalho da psicologia, o doente pode encontrar um melhor caminho para o enfrentamento da dor, do sofrimento e até mesmo de uma morte mais digna e menos sofrida. É importante criar as condições de comunicação nesse momento: o psicólogo deve buscar o "falar" do paciente, seja através de gestos, olhares ou gemidos, e ser seu porta-voz. ${ }^{12}$

A necessidade de um atendimento psicológico pode não ser percebida pelo paciente, pois suas preocupações estão dirigidas para o corpo e para as ações exploratórias e terapêuticas que nele são praticadas. Atribui seu mal-estar emo- 
cional às vivências oriundas deste corpo doente. ${ }^{6}$

As possíveis reações emocionais do paciente envolvem passividade ou agressividade, argumentação sobre aspectos sem importância, manifestações de raiva ou depressão pela dificuldade em aceitar não só sua doença, mas todo o processo de hospitalização e tratamento. Há também o medo da invalidez permanente, da dependência, da dor física, das alterações na autoimagem, da anestesia, em casos de cirurgia, e do próprio retorno para casa após a hospitalização. ${ }^{10} \mathrm{O}$ paciente, enquanto hospitalizado, costuma ficar mais introspectivo e reavaliar sua vida e seus valores.

Rincon e colaboradores ${ }^{13}$ identificaram em pacientes adultos de UTI índices elevados de transtornos psiquiátricos pré-existentes ou desencadeados/agravados pela doença (delirium: 7,3\%; depressão: $13,7 \%$; ansiedade: $24 \%$; e abuso de álcool: 37,9\%). Estes transtornos podem ser tratados por meio de intervenções psiquiátricas associadas a acompanhamento psicológico.

As questões psicológicas a serem abordadas devem ser focais, visando sempre àqueles aspectos estritamente relacionados à doença, às dificuldades adaptativas à instituição hospitalar, ao processo do adoecer e aos procedimentos diagnósticos. É importante ressaltar que, na UTI, ao contrário do que ocorre habitualmente, é o psicólogo quem procura o paciente, oferecendo-lhe ajuda e ficando disponível também para sua família. ${ }^{10,14}$

\section{O trabalho da psicologia com a família}

O impacto diante do adoecimento e internação de um familiar altera a forma de viver tanto do sujeito que está doente como de seus familiares, pois produz uma interrupção brusca do cotidiano. Isto altera toda a dinâmica familiar e gera sentimentos de insegurança, medo e incerteza. ${ }^{15}$

A família, angustiada e sofrida, que se sente impotente e assustada mediante a ameaça da morte, precisa da atenção do psicólogo, devendo ser envolvida no trabalho com o paciente, pois o vínculo com os familiares é, muitas vezes, uma das poucas motivações que ele tem para enfrentar o sofrimento. O psicólogo deve facilitar, criar e garantir a comunicação efetiva e afetiva entre paciente/família e equipe, identificando qual membro da família tem melhores condições intelectuais e emocionais para receber as informações sobre o doente. ${ }^{12,14}$

Ismae ${ }^{10}$ alerta para o fato de que muitos familiares podem expressar a necessidade de ver o paciente repetidas vezes. Isto pode indicar uma forma da família tentar reconstruir o vínculo quebrado com seu familiar e/ou um meio de lidar com a angústia pela falta do controle que ocorre quando o paciente está longe de seu campo visual.

No CTI do HUPE, desde sua inauguração, sempre foi permitida a visita diária de familiares, sem restrição de número (diferentemente do que ocorre em muitas UTIs) e, após a visita, o médico dá as notícias sobre o estado de seu paciente. Em situações particulares, nas quais um parente não possa comparecer na hora marcada (como em caso de trabalho), é sempre autorizada a visita num horário compatível. No entanto, em virtude da necessidade do paciente ser submetido a algum procedimento, nem sempre é possível permitir a entrada do familiar no horário previsto, causando nesta pessoa um elevado nível de angústia e ansiedade, uma vez que ela não está ciente destes acontecimentos.

De acordo com Botega, ${ }^{16}$ em um estudo realizado na França com 357 familiares de pacientes em UTI, observou-se que 35\% dos membros da família apresentavam depressão e $73 \%$ ansiedade.

Oliveira e Sommerman ${ }^{15}$ afirmam que uma das maiores fontes geradoras de ansiedade é a falta de informação ou informação excessiva e contraditória.

Os familiares precisam ser mantidos informados sobre o que acontece. Uma das maiores necessidades da família é o estabelecimento de uma comunicação clara, honesta e frequente com os membros da equipe que cuida do paciente. $^{17}$ 
É importante, segundo Santos, ${ }^{17}$ "que o profissional mostre atenção, empatia e carinho com o comportamento e sinais não verbais. A expressão facial, o contato visual, a distância adequada e o toque nas mãos, braços ou ombros ajudam a demonstrar empatia e oferecer apoio e conforto".

\section{Trabalho com grupo de familiares}

Em virtude da necessidade de aprimorar a atenção à família surgiu, no CTI geral do HUPE, em 1995, o grupo de informação e apoio. O objetivo deste grupo é promover um espaço para acolher medos, dúvidas e angústias dos familiares de pacientes. Por se tratar de um grupo terapêutico, torna-se possível uma melhor integração, compartilhamento de sentimentos, dúvidas e informações, pois é a partir das trocas realizadas ali, pela visão de outros casos mais graves (ou não), que os familiares conseguem perceber que não estão sozinhos e, consequentemente, podem aprender novas formas de adaptação.

O grupo funciona na sala de reunião da UTI, sob coordenação das psicólogas, com a presença do médico e, por vezes, de outro membro da equipe multidisciplinar (enfermeira, fisioterapeuta, nutricionista). O médico, após informar aos familiares o quadro clínico dos pacientes, em função de suas atividades, poderá ou não permanecer no grupo até o final do encontro.

É importante salientar que o grupo de suporte à família é aberto, pois a cada grupo novas famílias podem participar. Nos encontros, as dúvidas mais frequentes (relacionadas a procedimentos comumente efetuados) costumam ser sobre a traqueostomia e a gastrostomia e também sobre o "inchaço" apresentado por muitos pacientes (o que altera sua aparência, causando grande impacto nos familiares), além de questões ligadas à fisioterapia.

Com algumas interrupções, este grupo vem sendo realizado no CTI geral do HUPE aproximadamente há 12 anos. No momento não está ocorrendo, pois o mesmo encontra-se em reforma para ampliação de suas instalações; por este motivo a unidade está funcionando em local adaptado, no qual não há espaço físico apropriado que garanta a privacidade necessária para que os familiares sintam-se à vontade para trazer suas questões e manifestar suas emoções.

Consideramos de suma importância o trabalho de suporte psicológico aos familiares, pois estas pessoas, além de extremamente sofridas com a situação, têm muito a contribuir para a adaptação do paciente ao tratamento, funcionando como o elo entre o mundo externo do doente e o hospital e protegendo sua identidade fragmentada pela doença pela e internação. É incontestável que o familiar só poderá fornecer suporte adequado se tiver o apoio e o acolhimento necessários.

\section{O trabalho com a equipe da UTI}

A equipe de saúde também vivencia no seu cotidiano esse significado de viver e morrer, experimentando sentimentos ambivalentes de onipotência e impotência, sendo alvo de muitas cobranças por parte de todos os envolvidos e tendo que lidar com a percepção da própria finitude. O psicólogo deve atuar como facilitador do fluxo dessas emoções e reflexões, detectando os focos de estresse e sinalizando as defesas exacerbadas. ${ }^{18}$

A equipe deve estar preparada para lidar com sentimentos, emoções, valores morais e éticos, crença religiosa dos pacientes e familiares, de modo a respeitar e considerar as possíveis questões que emergirem. Este contato direto coloca os profissionais muitas vezes em situações que exigem um processo reflexivo sobre seus próprios valores, sua própria finitude e crença religiosa, bem como a angústia mediante a tomada de decisões.

Na UTI, um dos fatores adversos é a falta de tempo, o que dificulta o relacionamento interpessoal. Além disso, não é fácil para a equipe lidar com o sofrimento diário dos pacientes, familiares e com o seu próprio sofrimento. ${ }^{19}$

A comunicação entre o profissional e o 
doente, na maioria das vezes, não é clara. A dificuldade de falar por causa da cânula orotraqueal ou da traqueostomia torna-se mais um agravante, sendo necessária uma intervenção para auxiliar na comunicação. Uma boa estratégia é o atendimento conjunto com outros profissionais, promovendo um maior entendimento e melhor relacionamento, reduzindo desconfortos tanto da equipe como do paciente.

$\mathrm{Na}$ literatura atual, muitos estudos mencionam problemas frequentes relacionados à comunicação deficitária entre pacientes e a equipe de saúde. ${ }^{20}$ Quando há uma comunicação de qualidade entre profissional de saúde e paciente, este se sente mais motivado e encorajado a fazer perguntas, reduzindo seu sofrimento e ansiedade gerados pelo tratamento, além de se sentir mais satisfeito. ${ }^{21}$

É na prática do dia a dia que temos a oportunidade de aprender uns com os outros. Quando ocorre a mobilização da equipe em função de uma situação, seja com o paciente, seja com um familiar ou até mesmo com um membro da própria equipe, surge a oportunidade de trabalhar as questões emergentes. Por isso, é importante que o profissional de psicologia esteja atento e presente na UTI não só durante o período da visita, mas que ele participe das reuniões de equipe, permaneça na unidade após a saída dos familiares e participe do funcionamento de uma forma integral.

O trabalho do psicólogo é incessante e constitui um desafio, pois irá depender da demanda de cada profissional, que será diferente de acordo com o momento que estiver vivenciando; portanto, não existem regras rígidas. A forma de intervenção deverá ser criada, recriada e adaptada à medida que surgirem as necessidades de atuação da psicologia.

Quando o foco é a equipe, é importante não perder de vista o verdadeiro objetivo, que é a assistência. Um ambiente de trabalho com relações interpessoais adequadas torna-se mais agradável e produtivo, consequentemente gerando maior qualidade no atendimento aos pacientes e familiares.
Dentro de um trabalho grupal, o psicólogo precisa atuar como um agente facilitador do processo interativo, visando uma boa comunicação interpessoal.

Na tentativa de melhorar a comunicação e a relação entre todos os sujeitos envolvidos no CTI geral do HUPE, bem como discutir questões que permeiam as situações existentes em uma UTI, como a terminalidade, tivemos o ensejo de realizar palestras para a equipe multiprofissional, incluindo os residentes.

A oportunidade de a psicologia discutir com os profissionais através destes eventos permite uma melhor interação e troca de experiências entre os profissionais, ampliando ideias e promovendo reflexões importantes, favorecendo a resolução de problemas e ajudando na eficácia da comunicação.

O trabalho em equipe, principalmente dentro de uma instituição universitária, onde há um constante rodízio de estudantes, está sempre passando por modificações, o grupo está permanentemente em movimento, alterando sua dinâmica. Desta forma, o profissional de psicologia deve estar apto a lidar com as resistências e frustrações, sempre disposto a recomeçar.

A UTI, como ambiente de aprendizagem e atuação profissional, contribui, sobretudo, para o amadurecimento profissional e pessoal, uma vez que estimula o raciocínio clínico, conduz a uma reflexão crítica sobre conceitos e preconceitos relacionados com o viver e o morrer, a valores, à ética instrumental e dialógica, enfim às questões teórico-práticas da saúde e bioética no que se tem de mais diferencial e específico. ${ }^{22}$

\section{Conclusões}

A psicologia cumpre um relevante papel na UTI, visando a um atendimento que reconhece o paciente como um sujeito que possui desejos, medos e anseios, inserido em um contexto social, cultural e familiar com sua diversidade de aspectos psicológicos.

O trabalho com a família do paciente internado na UTI possibilita um lugar de escuta e intervenção em questões e mecanismos psi- 
cológicos que, se não trabalhados, poderão influenciar negativamente o paciente e sua doença.

No trabalho com a equipe, a psicologia fornece espaço para reflexão, suporte e apoio, favorecendo a percepção de questões que necessitam de elaboração e facilitando o fortalecimento dos vínculos entre o grupo de profissionais.

Enfim, o psicólogo funciona como facilitador das relações interpessoais dos sujeitos envolvidos, favorecendo uma comunicação mais eficaz, o que pode resultar em ambiente profissional mais agradável e melhor qualidade no atendimento aos pacientes e familiares.

\section{Referências}

1. Angerami-Camon VA. Tendências em psicologia hospitalar. 2. ed. São Paulo: Pioneira-Thomson Learning; 2004. p.1-29.

2. Pregnolatto AP, Agostinho VB. O psicólogo na unidade de terapia intensiva - Adulto. In: Batista MN , Dias RR, editores. Psicologia hospitalar: teoria, aplicação e casos clínicos. Rio de Janeiro: Guanabara Koogan;2003. p.93107.

3. Almeida EC. Psicólogo no hospital geral. Psicologia, Ciência e Profissão 2000;20(3):24-7.

4. Simão AT. Terapia Intensiva. Rio de Janeiro: Atheneu;1976. p.3-25.

5. Civetta J, Taylor R, Kirby R. Critical Care. Philadelphia: J.B. Lippincott Company;1988. p.247-54.

6. Mello FJ. Psicossomática hoje. Porto Alegre: Artes Médicas Sul:1992. p.353-83.

7. Ayres JRCM. Cuidado e reconstrução das práticas de saúde. Interface Comunicação Saúde e Educação 2004;8(14):73-92.

8. Campos TCP. Psicologia Hospitalar: a atuação do psicólogo em hospitais. São Paulo: EPU;1995. 112p.

9. Chiattone HBC, Sebastiani RW. A Ética em Psicologia Hospitalar. In: Angerami-Camon VA, organizador. A Ética na Saúde. São Paulo: Pioneira;1997.182p.

10. Ismael SMC. A inserção do psicólogo no contexto hospitalar. In: __. A prática psicológica e sua interface com as doenças. São Paulo: Casa do Psicólogo; 2005.p.17-36.

11. Simonetti A. Manual de Psicologia
Hospitalar: o mapa da doença. São Paulo: Casa do Psicólogo;2004. 201p.

12. Angerami-Camon VA, Trucharte FAR, Knijnik RB, Sebastiani RW, organizadores. Psicologia hospitalar: Teoria e prática. São Paulo: Pioneira;2006. p.15-28.

13. Rincon GH, Granados M, Unutzer J, Gomez M, Duran R, Badiel M, et al. Prevalence, detection na treatment of anxiety, depression and delirium in the adult critical care unit. Psychosomatics 2001;42(5):391-6.

14. Romano BW. Princípios para a prática da psicologia clínica em hospitais. São Paulo: Casa do Psicólogo;1999. p.115-67.

15. Oliveira EB, Sommerman RD. A família hospitalizada. In: Romano BW. Manual de Psicologia Clínica para Hospitais. São Paulo: Casa do Psicólogo;2008. p.217-23.

16. Botega NJ, Jacintho ACA, Damasceno BP, organizadores. Prática psiquiátrica no hospital geral: interconsulta e emergência. Porto Alegre: Artmed; 2006. p.395-404.

17. Santos FS. Cuidados Paliativos: discutindo a Vida, a Morte e o Morrer. São Paulo: Atheneu; 2009. p.223-44.

18. Angerami-Camon VA, organizador. Psicologia da Saúde: um novo significado para a prática clínica. São Paulo: Pioneira; 2002.p.215-25.

19. Leite DPM. Grupos em uma Unidade de Terapia Intensiva. In: Mello Filho J. Grupo e corpo. Porto Alegre: Artes Médicas; 2000. p.117-30.

20. Coyle N, Sculco L. Communication and the patient/physician relationship: a phenomenological inquiry. The Journal Of Supportive Oncology 2003 Set/Out [acesso 05 out 2012];1(3):206-15. Disponível em: http:// www.supportiveoncology.net/jso/journal/ articles/0103206.pdf

21. Savard M. Bridging the communication gap between physicians and their patients with physical symptoms of depression. Prim Care Companion J Clin Psychiatry 2004;6 (Suppl 1):17-24.

22. Pessini L, Barchifontaine CP. Dignidade e solidariedade no adeus à vida. In: Problemas atuais de bioética. 8. ed. São Paulo: Edições Loyola; 2008. p.198-201. 


\title{
Por uma rotina no transporte intra-hospitalar: elementos fundamentais para a segurança do paciente crítico
}

\author{
A routine for in-hospital transportation: \\ key elements for critically ill patient safety
}

\author{
Shirley A. Morais ${ }^{*}$
}

Luana F. de Almeida

\section{Resumo}

O transporte intra-hospitalar é um procedimento corriqueiro nas unidades de terapia intensiva e é frequentemente desvalorizado por acontecer dentro do ambiente hospitalar e ser acompanhado por profissionais durante seu percurso. Buscou-se investigar dinâmicas mais adequadas para a realização do transporte intra-hospitalar do paciente crítico, com vistas a estimular reflexões e possíveis adequações, por parte dos profissionais de saúde, acerca da segurança indispensável no transporte do paciente gravemente enfermo. Foram realizadas pesquisas nas bases de dados on-line Scientif Eletronic Library Online (SciELO), Literatura Latino-Americana e do Caribe (LILACS) e Medical Literature Analysis and Retrieval System Online (MEDLINE) disponíveis na Biblioteca Virtual de Saúde (BVS), do Ministério da Saúde/Brasil, além de publicações de órgãos e autores competentes sobre o assunto. Evidencia-se que o planejamento, a participação de profissionais qualificados e o uso de equipamentos adequados de monitorização são considerados essenciais para um transporte seguro, sendo fundamentais para a diminuição de intercorrências durante esse procedimento. Para melhor compreensão de todo o processo, o transporte intra-hospitalar pode ser dividido em três fases que são: o preparo do paciente, equipamentos e materiais; o transporte propriamente dito; e o regresso do paciente. A segurança do paciente durante todo o procedimento é necessária a fim de contribuir para o um melhor prognóstico. Pode-se observar, desta maneira, que a existência de um instrumento que norteie as ações dos profissionais quanto à realização do transporte intra-hospitalar é de suma importância para a segurança do paciente, sobretudo daquele internado em unidade de terapia intensiva (UTI). Diante de estudos e da indissociável necessidade da realização de transporte intra-hospitalar, verifica-se o quanto é imperativo a busca por meios para a redução e até mesmo a eliminação dos eventos adversos relacionados a esse procedimento.

Descritores: Transporte de pacientes; Segurança do paciente; Monitorização fisiológica. 


\section{Abstract}

Intrahospital transfer is a frequent procedure at Intensive Care Units usually underestimated as it is done by health professionals within hospital environment. We sought to investigate more appropriate dynamics to encourage reflection and potential adaptations by health professionals regarding the safety required to transfer critically ill patients. The following online databases were searched: Scientific Electronic Library Online (SciELO), Latin American and Caribbean Health Sciences (LILACS), and the Medical Literature Analysis and Retrieval System Online (MEDLINE), all available at the Virtual Health Library (BVS) of the Brazilian Ministry of Health. Besides, other publications from bodies and authors with expertise on the subject were consulted. Therefore, the planning, the participation of qualified professionals, and use of appropriate monitoring equipment are paramount for a safe transfer, playing a crucial role in reducing intercurrences during the procedure. For better understanding purposes, the intrahospital transfer can be divided into three phases, namely: preparation of the patient, equipment and materials; the transfer itself and the return of the patient to the unit of origin. The patient's safety during the entire procedure is essential to keep its purpose in contributing to a better prognosis. Hence, it is noticeable that the presence of an instrument that guides the actions to be taken by professionals in intrahospital transfers is critical for the patient's safety, especially those admitted in the ICU. Based on past studies and before the unavoidable need to perform intrahospital transfers, it becomes clear how imperative is to seek ways to reduce and even eliminate adverse events related to this procedure.

Keywords: Transportation of patients; Patient safety; Monitoring, physiologic.

\section{Introdução}

Os pacientes críticos portadores de afecções de alta complexidade requerem intervenções que, muitas vezes, são realizadas fora da unidade de terapia intensiva (UTI). Estes necessitam de transporte intra-hospitalar, ou seja, encaminhamento temporário para a realização de exames diagnósticos, procedimentos terapêuticos ou transferências realizadas por profissionais de saúde para outros setores, ainda que dentro do ambiente hospitalar. ${ }^{1}$

Embora esse procedimento seja corriqueiro nas UTIs, e acompanhado por profissionais durante toda sua realização, ele é frequentemente desvalorizado pelos profissionais de saúde. Além disso, a não padronização das ações para a garantia de uma adequada assistência nesse caso reflete na ocorrência de eventos adversos relacionados ao transporte de pacientes criticamente enfermos. ${ }^{2,3}$

Sabe-se da necessidade do transporte intra-hospitalar para a realização de exames complementares e intervenções cirúrgicas, as quais não podem ser realizadas à beira do leito. Sendo assim, a garantia da segurança do paciente durante esse procedimento é de extrema importância, com a intenção de prevalecer, dessa forma, os benefícios que devem ser almejados com o transporte intra-hospitalar. ${ }^{3,4}$

Em relação à minimização dos riscos e das possibilidades de eventos adversos, cabe destacar o respaldo da Resolução da Diretoria Colegiada (RCD) no 7 , que preconiza o acompanhamento contínuo, de pelo menos um enfermeiro e um médico durante o transporte intra-hospitalar de pacientes críticos, bem como a disponibilidade do prontuário do paciente durante esse procedimento. ${ }^{5}$

Diante do exposto, buscou-se investigar dinâmicas mais adequadas para a realização do transporte intra-hospitalar do paciente crítico, com vistas a estimular reflexões e possíveis adequaçoes, por parte dos profissionais de saúde, acerca da segurança indispensável no transporte do paciente gravemente enfermo. Desta maneira, foram realizadas pesquisas nas bases de dados on-line: Scientif Eletronic Library Online (SciELO), Literatura Latino-Americana e do Caribe (LILACS) e Medical Literature Analysis 
and Retrieval System Online (MEDLINE) disponiveis na Biblioteca Virtual de Saúde (BVS), do Ministério da Saúde/Brasil e publicações de órgãos e autores competentes sobre o assunto.

\section{Transporte intra-hospitalar e a segurança do paciente}

Embora seja uma prática comum, o transporte intra-hospitalar ainda é bastante temido pelos profissionais. O planejamento, a participação de profissionais qualificados e o uso de equipamentos adequados de monitorização, são considerados essenciais para um transporte seguro, sendo fundamentais para a diminuição de intercorrências durante esse procedimento. ${ }^{2}$ De fato, de acordo com autores como Japiassú ${ }^{2}$ e Zuchelo, ${ }^{3}$ a ocorrência e gravidade das complicações são proporcionais ao tempo de transporte e à falta de preparo dos profissionais.

Ainda que haja a possibilidade de complicações, constantemente é indispensável que os pacientes sejam levados para outros setores dentro de um mesmo hospital, para a realização de testes diagnósticos, como tomografia, ressonância nuclear magnética, angiografias. Também é preciso considerar o fato de que alguns dos setores para os quais os pacientes são transportados inspiram maior preocupação, devido à frequência com que ocorrem complicações. Pode-se citar como exemplo, a sala de tomografia, onde o paciente, por alguns momentos - durante o exame em si - deve permanecer sozinho, o que inviabiliza o acesso dos profissionais aos monitores e até mesmo de ouvir os alarmes. Esse procedimento, portanto, ainda que seja necessário, põe em risco a segurança do paciente. ${ }^{2}$

A garantia da integridade do paciente que necessita do transporte intra-hospitalar depende dos esforços de uma equipe multiprofissional composta basicamente por médico, enfermeiro e fisioterapeuta. Estes profissionais são responsáveis pela manutenção da vida do paciente durante o transporte, tendo cada um suas atribuições individuais e em equipe. De acordo com
Lamblet, ${ }^{7}$ as atribuições para esses profissionais podem ser definidas nos seguintes termos:

- Enfermeiro: avalia o paciente juntamente com o médico e outros profissionais; reúne e verifica a equipe necessária para o transporte, bem como equipamentos, materiais, medicações que irão acompanhar o paciente; realiza registros necessários no prontuário do paciente; após o retorno, monitoriza o paciente em seu leito na unidade e verifica a funcionalidade de dispositivos como drenos, sondas e cateteres; calibra e afere equipamentos necessários ao uso contínuo do paciente; registra informações referentes ao transporte como as intercorrências e condutas realizadas; verifica as novas prescrições médicas para o paciente.

- Fisioterapeuta: verifica o ventilador de transporte; acompanha o paciente ao setor de destino oferecendo suporte ventilatório adequado; registra as intercorrências e condutas realizadas durante o transporte em prontuário.

- Médico: avalia as condições do paciente, solicita os materiais e equipamentos necessários para o transporte; solicita a interpretação imediata dos estudos realizados e a necessidade de repeti-los; acompanha o paciente de alto risco em todo o transporte; registra as intercorrências e condutas e demais informações em prontuário.

Vale ressaltar que a presença desses profissionais pode variar de acordo com a gravidade do paciente. Na perspectiva de Pires, ${ }^{4}$ o número de envolvidos deve ser definido pela gravidade do paciente no momento do transporte, sendo, em todo caso, não inferior a dois profissionais. Já para pacientes que estejam hemodinamicamente instáveis, o autor afirma que a equipe deve ser composta minimamente por um médico, um enfermeiro, um técnico de enfermagem e um fisioterapeuta. Além disso, outros profissionais podem estar envolvidos como auxiliar de transporte e o enfermeiro do setor de destino. ${ }^{7}$ 


\section{Fases do processo do transporte intra-hospitalar}

A posição de alguns autores diverge quanto às fases do processo intra-hospitalar. ${ }^{4,6,7} \mathrm{Na}$ proposta de Pereira Jr. ${ }^{6}$ há a divisão do transporte intra-hospitalar em três fases, o que melhora a compreensão de todo o processo e ajuda na preparação da equipe e na prevenção de agravos para o paciente:

- Fase preparatória: deve haver uma comunicação eficaz entre o local de origem e o de espera; avaliação do paciente e sua condição atual; preparo da equipe que irá acompanhar o paciente, que deve ser composta por enfermeiro, médico, auxiliares ou técnicos de enfermagem e fisioterapeuta, caso esse paciente necessite de suporte ventilatório; avaliação da necessidade individual de equipamentos para o transporte de cada paciente.

- Fase de transferência: nesta fase o objetivo é manter o paciente hemodinamicamente estável; manter uma monitorização adequada e cuidados redobrados ao transferir o paciente de leito; controlar situações de emergência.

- Fase de estabilização pós-transporte: deve-se manter uma maior atenção aos parâmetros hemodinâmicos, pois o período de meia a uma hora depois é considerado extensão da evolução do transporte intrahospitalar, sendo necessário o registro dos parâmetros para melhor controle de qualidade.

Já Lamblet ${ }^{7}$ descreve as etapas do transporte intra-hospitalar articulada a uma classificação de risco e condição do paciente. Para o referido autor, as fases do transporte intra-hospitalar podem ser definidas como:

- Fase I: há a classificação dos pacientes para o transporte. Isto consiste em classificar o paciente quanto ao risco para o transporte intra-hospitalar em: baixo risco A (pacientes que não estejam dependentes de suporte ventilatório e estáveis nas últimas 24 horas); baixo risco B (pacientes que necessitam de suporte ventilatório, porém que se mantiveram estáveis nas últimas 24 horas) e alto risco $\mathrm{C}$ (pacientes que necessitam de suporte ventilatório e estão em uso de drogas vasoativas).

- Fase II: aqui há a definição da equipe que irá acompanhar o transporte, o preparo dos equipamentos e materiais necessários para o suporte do paciente.

- Fase III: transporte propriamente dito.

Nesta fase, há a saída e o retorno do paciente ao setor de origem.

Para Pires,${ }^{4}$ durante o transporte intra-hospitalar há a necessidade de definição das atribuições profissionais dos membros que irão compor a equipe durante o transporte intrahospitalar. Nesse sentido, tal procedimento pode ser dividido em três etapas que são:

- Planejamento: o enfermeiro deve estabelecer comunicação com o setor de origem, garantir a monitorização e manutenção hemodinâmica do paciente antes do transporte, garantir recursos físicos e equipe necessária. Deve haver ainda a divisão de atribuições, de forma clara, para cada componente da equipe e a comunicação do transporte à família, caso o horário do transporte ocorra em horário de visita.

- Fase de execução: a manutenção da estabilidade do paciente é o objetivo principal. Recomenda-se rápida inspeção de acessos venosos, drenos, bombas de infusão, ventilador e monitores, mantendo durante o transporte, vigília constante dos equipamentos e das informações fornecidas pela monitorização. Providenciar e organizar registros, prontuários e exames que sejam necessários à finalidade do procedimento. Essa fase tem seu término quando o paciente retorna ao setor de origem, sendo novamente restabelecido no leito.

- Fase de avaliação: na qual deve acontecer 
o registro de todos os dados do transporte, como intercorrências, eventos, condições clínicas do paciente durante e após o transporte, bem como a notificação de todos os eventos adversos.

Com isso, é possível observar que a despeito das divergências entre autores nas divisões de fases do transporte intra-hospitalar há uma complementação na descrição das dinâmicas necessárias para a garantia da segurança, além da demonstração do forte aspecto de complexidade que envolve esse procedimento. Esses pontos revelam ser imprescindível o adequado gerenciamento do transporte intra-hospitalar pela equipe, de forma que aconteça sem intercorrências ou eventos adversos para o paciente.

\section{Monitorização do paciente durante o transporte intra- hospitalar}

De acordo com Japiassú, ${ }^{2}$ deve existir um foco no processo de transporte baseado em rotinas, que consistem em estabilização hemodinâmica e equipamentos de suporte para o paciente, incluindo drogas necessárias a possíveis intercorrências. Em seu estudo, preconiza cuidados essenciais para três classificações de pacientes, que são:

- Paciente em ventilação mecânica: para estes pacientes, deve haver uma atenção centrada na manutenção da permeabilidade das vias aéreas, como a desobstrução e a garantia da ventilação contínua. Além disso, o tipo de ventilador e suas características devem ser suficientes para atender as necessidades de suporte.

- Paciente com choque: para estes pacientes, deve haver uma atenção centrada na estabilização hemodinâmica antes de sua saída da unidade, correção de distúrbios, acessos venosos calibrosos, monitorização contínua da pressão arterial (PA), em alguns casos invasiva, manutenção de drogas vasoativas em bombas infusoras, com baterias carregadas previamente e até mesmo não realizar o transporte, caso não se consiga a estabilização prévia desse paciente.

- Paciente neurológico: para estes pacientes, deve haver atenção especial para o requisito de imobilizações, manutenção da cabeceira elevada. Se possível, evitar rotações cervicais. Proteger vias aéreas, ofertar oxigênio, manter estabilidade hemodinâmica, corrigir distúrbios do sódio e anemia, verificar glicemia, disponibilizar drogas anticonvulsivantes e monitorizar a pressão intracraniana, se necessário.

A padronização do procedimento de transporte, segundo Wachter, ${ }^{8}$ contribui para a elevação dos níveis de segurança do paciente e possibilita a visualização de eventuais anormalidades. Nesse sentido, Japiassú ${ }^{2}$ aborda a necessidade de uma lista de tarefas, que tem por finalidade evitar intercorrências e/ou danos relacionados ao paciente. Refere, também, a necessidade de uma equipe para a realização do transporte, que inclui um médico, um técnico de enfermagem e um fisioterapeuta. Dentre as ações encarregadas a estes profissionais pode-se destacar:

1. avaliar setor de destino, definir setor de destino, estimar tempo de transporte, avisar setor de destino e elevadores;

2. prover materiais e drogas, tais como: máscara e bolsa para ventilação manual, tubos traqueais no 7,0 e 8,0, cateteres 14G-16G, laringoscópio e lâminas checados, luvas de procedimento e estéreis, seringas e agulhas de diferentes tamanhos. E ainda disponibilizar de drogas como adrenalina, atropina, amiodarona, midazolan, diazepam, soluções cristaloides, entre outras necessárias ao paciente;

3. providenciar monitor de transporte, com oximetria de pulso, cardioscópio e pressão não invasiva; ventilador de transporte para o paciente em ventilação mecânica; 
4. Verificar pressão arterial (PA), frequência cardíaca (FC), frequência respiratória (FR), saturação de oxigênio $\left(\mathrm{SatO}_{2}\right)$ antes, no destino e após chegada; manter infusões venosas indispensáveis; esvaziar coletores de urina e secreção gástrica; verificar fixações de tubos traqueais, acessos venosos e cateteres gástricos e vesicais; manter dreno torácico aberto em selo d'água e em posição inferior a do paciente; aspirar vias aéreas, verificar pressão expiratória final positiva (PEEP) e fração inspirada de oxigênio $\left(\mathrm{FiO}_{2}\right)$, mantendo os padrões ventilatórios antes da saída. Recomenda-se manter $\mathrm{FiO}_{2}$ em $100 \%$, verificar o nível de $\mathrm{O}_{2}$ no cilindro e imobilizar o politraumatizados.

Apesar da relevância de ações descritas pelo autor apresentado, corroboradas por outros, ${ }^{4,7}$ é importante destacar a não inclusão, por Japiassú, ${ }^{2}$ do profissional enfermeiro na equipe, o que contraria a RDC no $75,{ }^{5}$ que o aponta como indispensável para a realização de tal procedimento.

Atrelado aos instrumentos, que objetivam a estabilidade hemodinâmica e a segurança do paciente, vários autores chamam atenção para a necessidade de qualificação e capacitação profissional. ${ }^{1,2,7,6,9,10,11}$ Esse preparo da equipe seria indispensável para que o transporte intra-hospitalar ocorra de forma correta e sem oferecer agravos à saúde do paciente, conservando sua finalidade de contribuir para a terapêutica empregada.

A falta e a consequente necessidade de estudos brasileiros sobre o assunto também é afirmada por alguns autores. ${ }^{1,10}$ Parte da produção científica sobre o tema é internacional, o que dificulta o acesso a informações importantes para os profissionais, além do fato dessas produções, muitas vezes, refletirem situações locais, que não podem ser generalizas. Partindo desse pressuposto, Nogueira, ${ }^{1}$ apresenta em seu estudo, a criação de um site avaliado por profissio- nais de enfermagem, de acesso ilimitado, sobre o transporte intra-hospitalar, com o objetivo de facilitar o acesso rápido dos profissionais a informações que norteiam conhecimento e a realização de uma prática segura.

\section{Eventos adversos e alterações hemodinâmicas relacionados ao transporte de pacientes}

Verifica-se uma escassez de dados nas fontes pesquisadas para a elaboração do presente estudo, sobre a incidência de eventos adversos no transporte intra-hospitalar, principalmente no que se refere a estudos nacionais sobre o tema, o que dificulta uma análise mais acurada.

O transporte intra-hospitalar tem como objetivo final trazer benefícios para ao paciente, seja pela realização de procedimentos, seja de exames. Dessa forma, a estabilidade do paciente deve ser assegurada. As alterações hemodinâmicas são esperadas, porém devem ser monitorizadas e evitadas. Entre as alterações mais evidenciadas e abordadas nos estudos, citam-se as cardiorrespiratórias e termorregulatórias, essa última especificamente em neonatos. ${ }^{2,3,10,11}$

Almeida $^{12}$ também constatou a escassez de estudo sobre o tema, principalmente de estudos atuais e nacionais. Em sua análise, a autora identificou que a ocorrência dos eventos adversos no transporte intra-hospitalar variavam de $30 \%$ a $70 \%$. Os resultados revelaram que os eventos mais encontrados foram alterações fisiológicas do paciente, problemas na equipe multidisciplinar envolvida no transporte, comunicação interequipe e falha de equipamentos.

Em um estudo realizado em uma unidade de terapia intensiva neonatal, Vieira e colaboradores ${ }^{10}$ avaliaram 502 transportes intra-hospitalares com menores de 1 ano e 5 meses. Foram identificadas alterações termorregulatórias em $17,8 \%$ dos pacientes, com destaque predominante para hipotermia. Verificou-se ainda que $64 \%$ dos transportes intra-hospitalares objetivaram a realização de exames de diagnóstico por imagens; $42 \%$ 
o eletroencefalograma e $24 \%$ procedimentos cirúrgicos, entre outros. A duração do transporte em média, foi superior a uma hora, em todos os anos de estudo.

A mesma autora, em 2011, publicou outro estudo no qual avaliou 1.191 transportes intra-hospitalares durante 12 anos com crianças até 1 ano de idade e que pesavam menos de dez quilos. Evidenciou que mais de $27 \%$ dos transportes apresentaram intercorrências clínicas, entre estas 15,3\% foram por hipotermia; $5,5 \%$ por hiperóxia; $4,2 \%$ por dessaturação; $4,2 \%$ por necessidade de aumentar o suporte ventilatório; $1,4 \%$ por hipertermia; $1,4 \%$ por hiperglicemia e $1 \%$ por apneia. Em 6,6\% dos transportes ocorreu mais de uma intercorrência. Em todos os casos a duração do transporte foi em média superior a uma hora. Vieira e colaboradores ${ }^{10}$ verificaram ainda neste estudo, que, $22,6 \%$ dos transportes intrahospitalares ocorreram para a realização de cirurgias; 20,9\% para realização de tomografia; $18,2 \%$ para exames contrastados; $10,6 \%$ para ressonância magnética, entre outros. Apesar de existir diferenças fisiológicas significativas entre adultos e crianças, devemos enfatizar que qualquer paciente está propenso a alterações hemodinâmicas e que estas devem ser de conhecimento do profissional.

Fanara e colaboradores ${ }^{9}$ realizaram uma pesquisa em bases de dados on-line, na qual verificaram os principais eventos adversos, identificados por outros autores. Agrupou-os em: cardiocirculatórios, como hipotensão severa ou hipertensão, arritmias, parada cardíaca e morte do paciente; respiratórios, como hipóxia severa, broncoespasmo, pneumotórax, extubação, intubação seletiva e desincronização entre paciente e ventilador; neurológicos, como agitação e hipertensão intracraniana; hipotermia; falha de equipamentos, como falha elétrica e término do oxigênio e erros humanos. Além disso, objetivou verificar os principais fatores abordados para a prevenção dos eventos adversos, destacando-se entre estes: planejamento prévio do transporte e avaliação de sua necessidade; preparo e mo- nitorização adequada do paciente; verificação de equipamentos; equipe treinada; uso correto de protocolos e fácil acesso ao local de destino.

Em uma pesquisa de análise gasométrica realizada por Lima Jr. e colaboradores, ${ }^{13}$ com 23 pacientes adultos no pós-operatório imediato de cirurgia cardíaca, avaliou-se resultados obtidos antes e depois do transporte intra-hospitalar, utilizando dois métodos de ventilação: o ventilador de transporte e a respiração por ressuscitação manual autoinflável. Os melhores resultados foram revelados pelo grupo assistido através do ventilador de transporte, existindo diferenças significativas do potencial hidrogeniônico $(\mathrm{pH})$, pressão parcial de dióxido de carbono do sangue arterial $\left(\mathrm{PaCO}_{2}\right)$, pressão parcial de oxigênio do sangue arterial $\left(\mathrm{PaO}_{2}\right)$ e $\mathrm{SatO}_{2}$. Os autores comprovaram, dessa forma, que os pacientes em pós-operatório imediato de cirurgia cardíaca que utilizaram a ventilação mecânica, tiveram benefícios ao usar essa modalidade de suporte ventilatório, em detrimento do suporte por ventilação manual autoinflável. Dessa forma, fica clara a indicação de suporte ventilatório através da ventilação mecânica para este grupo.

Kim e colaboradores ${ }^{14}$ também consideram que o transporte pode apresentar risco significativo, principalmente para pacientes criticamente enfermos que estão necessitando de suporte ventilatório por meio de tubo endotraqueal (TET), pois a movimentação e mudanças de posição do paciente podem interferir na posição do TET.

Em outro estudo, com pacientes que necessitavam de suporte ventilatório, Mazza e colaboradores ${ }^{15}$ avaliaram 37 transportes, a fim de determinar se o transporte desses pacientes poderia ser realizado com segurança, baseado na avaliação dos parâmetros hemodinâmicos e respiratórios antes e após o transporte. $\mathrm{O}$ autor evidenciou que em 32,4\% dos transportes ocorreram complicações. De acordo com os resultados obtidos, ele concluiu que o transporte intra-hospitalar pode ser realizado com segurança e que este também está vinculado à presença de equipe multidisciplinar e equipamentos 
adequados para a realização do procedimento.

Zuchelo ${ }^{3}$ avaliou 58 transportes intra-hospitalares em dois hospitais, abordando as repercussões cardiorrespiratórias e eventos adversos em pacientes que estavam submetidos à ventilação invasiva durante o procedimento do transporte intra-hospitalar. Dos 58 transportes $87,53 \%$ tinham a finalidade da realização de tomografia; $67,2 \%$ apresentaram alterações cardiorrespiratórias relevantes; $13 \%$ estavam em uso de drogas vasoativas. O estudo mostrou ocorrências de eventos adversos em 44 transportes, totalizando 112 episódios de eventos adversos, relacionados à falhas de equipamentos e de equipes, predominando problemas com baterias e comunicação profissional. Além disso, o autor ressalta a precária monitorização disponível para o paciente durante o transporte, baseada apenas em oxímetro de pulso.

Diante dos resultados obtidos nos referidos estudos os autores concordam com a necessidade da criação de protocolos que padronizem o transporte-hospitalar com vista a nortear a prática e garantir a segurança do paciente. , $, 711,12^{12}$ Para Almeida, ${ }^{12}$ a segurança do paciente está intimamente ligada à criação de barreiras que impeçam a ocorrência e/ou reduzam eventos adversos.

Pode-se observar, desta maneira que a existência de um instrumento que norteie as ações dos profissionais quanto à realização do transporte intra-hospitalar é de suma importância para a segurança do paciente, sobretudo daquele internado em UTI.

\section{Conclusão}

Conforme os autores referenciados, a garantia da eficiência da ação de transportar um paciente, sobretudo aquele em estado grave, perpassa o preparo da equipe e o adequado planejamento das fases envolvidas nesse processo. O detalhamento e a importância dada às etapas, aos papéis e às ações de todos os profissionais responsáveis indicam a relevância de uma atenção especial a esse tipo de procedimento e seus potenciais riscos. Diante de estudos e da indissociável necessidade da realização de transporte intra-hospitalar, verifica-se quanto é imperativo buscar meios para a redução dos altos índices de eventos adversos relacionados a esse procedimento.

A otimização do transporte intra-hospitalar e a minimização dos possíveis eventos adversos podem ser alcançadas, portanto, com a aplicação dos devidos recursos de monitorização hemodinâmica durante todo o processo, abrangendo o momento anterior ao transporte em si, o transporte propriamente dito e o período posterior. Desta forma, há necessidade de se garantir suporte humano e tecnológico para responder, de maneira direta e ágil, às demandas que emergem de um momento à princípio tão corriqueiro, mas que revela uma face que carece de maior padronização.

A necessidade da realização de novos e mais específicos estudos se mostra pertinente, de modo que a busca pela segurança do paciente, tema bastante discutido atualmente, possa ser o foco de uma assistência de qualidade e livre de riscos. Nesse sentido, o transporte intrahospitalar realizado com pacientes admitidos na UTI deve primar pela manutenção da vigilância e observação contínua, não contradizendo ao que se espera e observa nesse contexto.

\section{Referências}

1. Nogueira VO, Marin HF, Cunha ICKO. Informações on-line sobre transporte intrahospitalar de pacientes críticos adultos. Acta Paul Enferm. 2005;18(4):390-6.

2. Japiassú AM. Transporte intra-hospitalar de pacientes graves. Rev Bras Ter Intensiva. 2005;17(3):217-20.

3. Zuchelo LTS, Chiavone PA. Transporte intra-hospitalar de pacientes sob ventilação invasiva: repercussões cardiorrespiratórias e eventos adversos. J Bras Pneumol. 2009;35(4):367-74.

4. Pires OS, Gentil RC. Transporte de pacientes críticos. In: Padilha KG, Vattimo MFF, Silva SC, Kiamura M. Enfermagem em UTI: cuidando do paciente crítico. Barueri, SP: Editora: Manole; 2010. p.917-43.

5. Brasil. Ministério da Saúde. $\operatorname{RDC} \mathrm{n}^{\circ}$ 7, de 24 de fevereiro de 2010. Dispõe sobre os 
requisitos mínimos para funcionamento de Unidades de Terapia Intensiva e dá outras Providências. Diário Oficial da União. $25 \mathrm{fev}$ 2010. Seção 1:48. [acesso em 20 outubro 2012]. Disponível em: http://www.saude.mg.gov. br/atos_normativos/legislacao-sanitaria/ estabelecimentos-de-saude/uti/RDC-7_ ANVISA\%20240210.pdf

6. Pereira Júnior GA, Carvalho JB, Ponte Filho AD, et al. Transporte intra-hospitalar do paciente crítico. Medicina (Ribeirão Preto) 2007;40(4):500-8.

7. Lamblet LCR, Teixeira AP, Correa AG. Transporte intra-hospitalar de pacientes graves. In: Knobel E. Terapia Intensiva Enfermagem. São Paulo: Editora Atheneu; 2009. p. 85-92.

8. Wachter RM. Princípios básicos em segurança do paciente. In: Knobel E. Compreendendo a segurança do paciente. Porto Alegre: Editora: Artmed; 2010. p. 35-44.

9. Fanara B, Manzon C, Barbot O, Desmettre T, Capellier G. Recommendations for the intrahospital transport of critically ill patients. Crit Care. 2010;14(3):R 87

10. Vieira ALP; Guinsburg R; Santos AMN; Peres CA; Lora MI; Miyoshi MH. Transporte intrahospitalar de pacientes internados em UTI neonatal: fatores de risco para intercorrências. Rev Paul Pediatr. 2007;25(3):240-6.
11. Vieira ALP, Santos AMN, Okuyama MK, Miyoshi MH, Almeida MFB, Guinsburg R. Fatores associados à hipotermia durante o transporte intra-hospitalar em pacientes internados em Unidade de Terapia Intensiva Neonatal. Rev Paul Pediatr. 2011;29(1):13-20.

12. Almeida ACG, Neves ALD, Souza CLB, Garcia JH, Lopes JL, Barros ALBL. Transporte intrahospitalar de pacientes adultos em estado crítico: complicações relacionadas à equipe, equipamentos e fatores fisiológicos. Acta Paul Enferm. 2012;25(3):471-6.

13.Lima Junior NA, Bacelar SC, Japiassú AM, Cader SA, Lima RCF, Dantas EHM, et al. Gasometria arterial em dois diferentes métodos de transporte intra-hospitalar no pós-operatório imediato de cirurgia cardíaca. Rev Bras Ter Intensiva. 2012;24(2):162-6.

14. Kim JB, Jung HJ, Lee JM, Im KS, Kim DJ. Barotrauma developed during intra-hospital transfer-A case report- . Korean J Anesthesiol. 2010;59(suppl):218-21. http://dx.doi. org/10.4097/kjae.2010.59.S.S218

15. Mazza BF, Amaral JLG, Rosseti H, Carvalho RB, Senna APR, Guimarães HP, et al. Segurança do transporte intra-hospitalar avaliação dos parâmetros hemodinâmicos e respiratórios. Estudo prospectivo de coorte. São Paulo Med J. 2008;126(6):319-22. 


\title{
Terminalidade humana na UTI: reflexões sobre a formação profissional e ética diante da finitude
}

\author{
Human terminality in ICU: \\ reflections on professional training and ethics in the face of finitude
}

Luana F. de Almeida*

\section{Resumo}

Profissionais de saúde convivem, no contexto da unidade de terapia intensiva (UTI), mais diretamente com os pacientes graves e seus familiares e lidam constantemente com a presença de suporte biotecnológico a órgãos vitais, isto é, entre possibilidades de manutenção da vida e enfretamento da morte. Diante dessa realidade, surgem profundas tensões emocionais relacionadas às expectativas e frustrações advindas da luta cotidiana contra a finitude humana. No entanto, observa-se, no processo de formação dos diferentes profissionais atuantes em terapia intensiva, a ausência de qualquer abordagem nas diferentes disciplinas que discutam aspectos cognitivos e afetivos relacionados ao processo da morte. Ainda que a reflexão sobre os aspectos envolvidos no melhor preparo para lidar com a morte seja estimulada por diversos autores, é inegável que as escolas de formação em saúde ainda enfrentam dificuldades para assumir o compromisso educacional com essa temática. Tal realidade demonstra a falta de repertórios adequados para lidar com decisões inerentes à atuação dos profissionais de saúde: a determinação de quem ocupa um leito - de quem vive e de quem morre - corresponde e resgata dilemas éticos a serem tratados. Isto implica uma discussão multidisciplinar no ambiente de formação e de atuação, o que explica a crescente presença de profissionais da psicologia e da saúde mental nas UTIs, abrindo espaço para a discussão da morte com os membros da equipe de saúde, que frequentemente lidam com sentimentos de perda, sofrimento, dor e fracasso, mas também com os pacientes e seus familiares. Nesse panorama, é possível perceber a importância, complexidade e especificidades das situações vividas por profissionais de saúde e pacientes no contexto de uma UTI. A sistematização de discussões relacionadas ao tema da morte pode constituir um meio eficaz de articulação entre a prática vivenciada e as perspectivas pessoal e profissional de médicos, enfermeiros, fisioterapeutas, entre outros, que testemunham ou testemunharão o complexo morrer humano.

Descritores: Morte; Educação; Unidades de terapia intensiva; Bioética. 


\section{Abstract}

In an intensive care unit environment (ICU), healthcare professionals live in straight contact with critically ill patients and their relatives, also continuously dealing with the presence of biotechnological support to vital organs, possibilities of life maintenance, and coping with death. Given this reality, deep emotional tensions arise from expectations and frustrations stemming from the daily fight against the supposed enemy - human finitude. However, throughout the process of qualification of the different intensive care therapy professionals, the absence of any approach from various disciplines to discuss cognitive and affective aspects related to the process of death is evidenced. Even if the reflection about the factors involved in the best preparation to cope with death is encouraged by many authors, it is undeniable that health training institutions still struggle to take over an educational commitment with this subject. Such reality evidences the lack of appropriate repertoire to deal with decisions inherent to the performance of healthcare professionals: the determination of who lies on a bed, of those who live or die corresponds to ethical dilemmas to be addressed. That entails a multidisciplinary discussion, both in health training institutions and in healthcare work environments - which explains the growing presence of psychology and mental healthcare professionals in ICUs - making room for talking about death with healthcare team members who often deal with feelings of loss, pain, and failure, but also with patients and their relatives. In this scenario, it is possible to realize the importance, complexity and specificity of situations experienced by healthcare professionals and patients within an ICU context. The systematization of discussions related to death can be an effective alternative to articulate hands-on experiences with personal and professional perspectives from physicians, nurses, physiotherapists, among others, who witness or will witness the complex death of human beings.

Keywords: Death; Education; Intensive care units; Bioethics.

\section{Introdução}

No desempenhar do seu papel de salvar vidas, os profissionais de saúde vivenciam, no contexto específico da UTI, possibilidades de sucesso ou fracasso, pautando suas ações em complexas decisões potencializadas pelas características desse ambiente. Além da presença de suporte a órgãos vitais e possibilidades de manutenção da vida, esses profissionais convivem mais diretamente com os pacientes graves e seus familiares, sendo, também, frequentemente questionados por esses sobre a evolução da doença, perspectivas de tratamento e expectativas de vida dos pacientes. Essas situações podem criar circunstâncias angustiantes relacionadas com a proximidade da finitude humana e a impossibilidade de dominá-la. Assim, as manifestações presentes nos profissionais se relacionam às exigências ligadas à sua função e às maneiras pelas quais essas mesmas exigências são sentidas por cada um deles. São comuns os sentimentos de culpa relacionados à incapacidade de evitar a morte e ao alto grau de exigência de suas próprias responsabilidades. ${ }^{1}$

Observa-se que as UTIs, ao mesmo tempo em que correspondem a setores nos quais a realização de procedimentos e cuidados é intensa, também correspondem a espaços naturalmente mobilizadores de emoções e sentimentos que, frequentemente, se manifestam de forma muito expressiva. O estresse atinge a todos, ou seja, pacientes, família, médicos, enfermeiros, fisioterapeutas e outros profissionais. Esses elementos vivem um clima de constante tensão, resultante do contato com a iminência de algum risco e/ ou desequilíbrio no estado dos pacientes, das demandas e solicitações que devem ser respondidas com presteza, da realização de grande número de procedimentos complexos e do ritmo intenso de trabalho. Trata-se de uma vivência simultânea de onipotência e impotência que pode gerar nos intensivistas sentimentos complexos e ambíguos de segurança e insegurança, certeza e incerteza, frente à tarefa de salvar vidas.

Desta maneira, percebe-se que o dia a dia na UTI se mostra polarizado por situações an- 
tagônicas na qual, às vezes, é possível salvar ou curar, e em outras, prorroga-se o sofrimento e confronta-se a presença da morte. Os profissionais, muitas vezes, são submetidos às pressões e dilemas éticos quanto à tomada de decisões em momentos críticos, como a questão sobre o prolongamento ou não da vida em casos sem prognóstico. Toda essa demanda gera a necessidade de uma formação específica para lidar com situações nas quais, rotineiramente, os profissionais de terapia intensiva estão envolvidos.

\section{O trabalho na UTI}

O que representa ou assinala uma ameaça à vida exige uma intervenção imediata dos profissionais intensivistas, como é o caso de uma diminuição nos batimentos cardíacos e outros sinais clínicos (um sangramento evidente, por exemplo). A noção de prioridade é estabelecida por esses profissionais e costuma ser formada a partir de uma apreciação baseada em protocolos ensinados nos manuais de rotina, que descrevem as etapas dos procedimentos terapêuticos a serem seguidos para os problemas de saúde mais comuns no atendimento ao paciente com risco de vida e/ou iminência de morte.

Pitta $^{2}$ assinala a variedade de situações extremas às quais os intensivistas estão intermitentemente submetidos: “(...) a solicitação constante de decisões rápidas e precisas; a necessidade de um grande número de informações serem processadas num curto espaço de tempo; a imensa responsabilidade em ter "uma vida nas mãos"; a tarefa desumana de "selecionar" quem usa este ou aquele equipamento; as situações de intercorrências inesperadas no quadro clínico dos pacientes, proporcionando um estado de alerta permanente; e o contato com a morte em tarefa diária”.2

No meio de um complexo conjunto de ações, na UTI, rotina e urgência se alternam. Notam-se momentos nos quais a tensão cresce ou o grupo profissional que ali atua entra em dinâmicas muito especiais e características profissionais e pessoais se manifestam. Como, por exemplo: na chegada de um paciente em estado crucial que exige decisões e ações de alta importância; no conflito de interpretação de uma situação: "deve ser feito isto ou aquilo?"; na interferência da família que quer ver o paciente e sofre impactos pelo seu estado de saúde; na não aceitação por parte do paciente de grave situação; nos agravamentos do quadro clínico e/ou na percepção de que algo vai muito mal a despeito de todos os cuidados; e na iminência da morte ou morte efetiva.

Na UTI, os profissionais de saúde, ocupando lugar e papéis distintos, participam do atendimento ao paciente com risco de vida e/ ou iminência de morte. A interdependência e a interligação de suas apreciações e avaliações desenham uma corrente dinâmica de decisões e ações que, afinal, determinam a qualidade dos cuidados prestados em termos de rapidez e eficácia. Isto, de fato, caracteriza o trabalho na UTI como produto da equipe multiprofissional intensivista, mas não retira o sentimento de responsabilidade profissional individual e a eventual culpa oriunda de alguma situação que possa ter saído do seu controle.

De fato, no processo de formação de profissionais de saúde, a terminalidade humana não é tema de ação pedagógica para que se desenvolvam comportamentos adequados em relação à situação da morte de um paciente ou de um paciente com diagnóstico grave. Observa-se, no processo de formação nos diferentes profissionais atuantes em terapia intensiva, a ausência de qualquer abordagem nas diferentes disciplinas que discutam aspectos cognitivos e afetivos relacionados ao processo da morte e do morrer. Ainda que a reflexão sobre os distintos aspectos envolvidos no ensino da morte seja estimulada por diversos autores, é inegável que as escolas de formação em saúde ainda enfrentam dificuldades para assumir o compromisso educacional com essa temática. Poucas oferecem disciplinas que tratem do tema da morte e, quando o fazem, geralmente são disciplinas eletivas ou de carga horária restrita. ${ }^{3,4,5,6,7}$ 


\section{Aspectos da finitude humana na UTI}

O processo de tomada de decisões médicas relativas à vida e morte dos pacientes de UTI se revela de extrema complexidade na avaliação prática do intensivista sobre o paciente. Através da tecnologia, consegue-se hoje postergar, prorrogar a vida. A ciência médica atingiu um patamar de desenvolvimento tecnológico que permite certo domínio e regulação da morte, em outras palavras, uma "domesticação" da morte. ${ }^{8}$

O desenvolvimento técnico das últimas décadas possibilitou suporte a órgãos humanos e funções vitais. Cada vez mais, realizam-se pesquisas voltadas para a obtenção de aparelhos que possibilitem manter vivos os homens. Na UTI, a morte, processo natural da vida, pode ser levada a ocorrer fora do tempo real, projetada para o futuro através de aparelhos que conseguem, contemporaneamente, prolongar a vida com a ilusão de dar crédito à imortalidade.

O paciente, nesse contexto, é constantemente monitorizado. Não é mais um ser humano autônomo, as máquinas fazem parte dele. Sem elas, em alguns momentos, ele não seria capaz de viver. O objetivo é colocar o paciente com alto risco de vida e/ou iminência de morte em um ambiente em que suas funções vitais são continuamente monitoradas, e onde a intervenção salvadora possa ser feita rapidamente, de forma concentrada e intensa, em um único lugar. Esse progresso da medicina intensiva se deve ao avanço da tecnologia biomédica.

Assim, nas UTIs, bem como em outros setores do hospital, o objetivo é suplantar a morte. Há regras e funções estipuladas, predeterminadas para o alcance da vitória sobre o pretenso inimigo. Os atarefados profissionais envolvidos na luta contra a morte, muitas vezes, assustam -se com seus limites e impotência. Nesse contexto, a eficiência técnica da máquina é colocada à disposição do paciente, significando a decisão de que esta acabou de penetrar nos limites biológicos da morte. Desta forma, a morte deixa de ser pontual, definitiva e privada, passando a se integrar nas políticas de intervenção sobre a vida.

Nesse espaço, a partir dos avanços da biomedicina, a morte passa a ser encefálica, biológica e celular. A finitude humana é dividida, parcelada numa série de pequenas etapas, como afirma Airès, ${ }^{8}$ entre as quais, definitivamente, não se sabe qual é verdadeiramente a morte, aquela em que se perde a consciência ou aquela em que se perde a respiração. Essa subdivisão, como refere Kovács, ${ }^{9}$ torna-se relevante quando envolve a polêmica dos transplantes, em que pacientes com morte cerebral são mantidos vivos para que os órgãos possam ser retirados e utilizados em uma nova vida. O momento da morte ou a interrupção da vida, nesses casos, passa a ser acordado entre os médicos, familiares e outros profissionais.

Compreende-se, desse modo, que através do emprego da tecnologia médica para a sustentação do viver, com a criação e utilização do respirador artificial, ocorreram profundas alterações, tanto no processo de morrer, quanto no próprio conceito de morte. O conceito de morte cerebral, como descrito anteriormente, é articulado ao transplante de órgãos. ${ }^{10}$ A morte de distintas partes do corpo de um indivíduo é possível através da tecnologia médica. Assim, a imagem da morte com o tradicional esqueleto com foice foi substituída, no século XX, pela imagem de um paciente internado na UTI, conectado a tubos e cercado de aparelhos que mantêm a vida. Este modelo de morte é denominado "morte moderna", medicalizada. ${ }^{8}$

Com tantos desequilíbrios, incertezas e paradoxos, na UTI facilmente se passa da luta pela vida à morte resignada; do desafio que se impõe em manter o paciente vivo ao medo da sua própria morte. Nada é permanente nesse contexto. Trata-se de um espaço ambíguo, no qual se procura controlar, através mesmo da negação e isolamento, o imprevisível.

\section{Bioética na UTI}

Observa-se que a morte na UTI se encaixa no que refere Airès, ${ }^{8}$ ou seja, a morte, no con- 
texto hospitalar, consiste em fenômeno técnico, causado pela parada dos cuidados, mais ou menos declarada, por decisão do médico e da equipe de saúde. São eles os donos da morte, do seu momento e de suas circunstâncias. A variabilidade da duração da morte é estabelecida pelos progressos da biomedicina. Dentro de certos limites, pode-se abreviá-la ou estendê-la, dependendo da decisão do médico e dos equipamentos disponíveis. Conjugadas à manutenção da vida surgem novas questões: quando podem ou devem ser desligados os aparelhos de manutenção da vida? Quais os critérios na tomada de decisões? Quais os atores envolvidos e os papéis desempenhados no processo decisório?

Os problemas éticos começaram a existir com os pacientes que não têm chance de se recuperar facilmente e ficam muito tempo na UTI, com suas funções vitais mantidas artificialmente. Esse fato não havia sido previsto na ideia fundamental da UTI, cuja filosofia é cuidar muito intensamente, por pouco tempo. Para esses pacientes, imersos em contradições e dilemas da tecnologia e da ética, a vida é discutível. Os custos explodem. Uma estadia em uma UTI apresenta um alto ônus financeiro e não resulta necessariamente em cura ou alta.

A bioética, então, surge na UTI como forma de reflexão para os profissionais intensivistas, associada à ação integrada da tecnologia do saber. A decisão de quem ocupa um leito, de quem vive e quem morre corresponde, certamente, a uma realidade a ser tratada. A morte passa a ser discutida. Surgem debates acerca dos termos eutanásia, ortotanásia e distanásia. Como indica Torres, ${ }^{11}$ a morte correta (ortotanásia), em seu tempo certo, nem abreviada (eutanásia), nem prolongada no tempo (distanásia), confronta médicos e enfermeiros num imperativo ético de reflexão sistemática sobre as posições assumidas por estes quanto aos tempos de morte dos pacientes na UTI.

Kovács, ${ }^{4}$ psicóloga, estudiosa dos assuntos da morte e do morrer, menciona que ao se priorizar no hospital, em especial na UTI, o salvar o paciente a qualquer custo, a ocorrência de morte pode fazer com que o trabalho de médicos e enfermeiros, nesse contexto, seja percebido como frustrante, desmotivador e sem significado. A psicóloga acrescenta que esta percepção pode ser agravada quando os procedimentos médicos a serem realizados, fora de possibilidade de cura, não são compartilhados com toda a equipe. Por outro lado, não conseguir evitar ou adiar a morte pode trazer ao profissional a vivência de seus limites, $o$ que, em algumas vezes, pode ser extremamente doloroso.

Situações geradoras de grandes dilemas éticos podem levar pacientes (se conscientes), familiares e profissionais a se depararem com a necessidade de tomada de decisão, no que concerne ao prolongamento ou interrupção das medidas terapêuticas. Delimitar o tratamento e definir ações correspondem a difíceis decisões, nem sempre concordantes e uniformes.

\section{A morte como um assunto a ser discutido}

Estudiosos do assunto, tanto na literatura nacional como internacional, concordam sobre a necessidade de se discutir amplamente todas as alternativas terapêuticas possíveis para a solução dos dilemas éticos inerentes ao tratamento intensivo e a terminalidade humana. Recomenda-se que a discussão seja interdisciplinar, agregando tantos profissionais quanto possível. $^{12,13}$

$\mathrm{Na}$ prática, no entanto, tal procedimento ainda é pouco observado e, na maioria das vezes, o médico é levado a decidir isolada e unilateralmente, não compartilhando opiniões devido à falta de comunicação entre os profissionais. Percebe-se, também, que a decisão de se interromper ou prolongar determinado tratamento nem sempre é consensual e sustentada pelos diferentes intensivistas da mesma instituição. Dessa forma, não é incomum que em plantões diferentes, um outro médico retome o tratamento anterior, motivado por suas convicções pessoais, criando um círculo vicioso de difícil solução e que reflete a falta de diálogo entre a 
própria equipe médica. Tais condutas, indesejáveis e contraditórias, não só confundem profissionais e familiares, como podem aumentar ou trazer falsas expectativas em relação à evolução clínica do paciente.

Diante disso, surgem algumas questões: Como comunicar aos pacientes e aos seus familiares o agravamento da doença e a proximidade da morte? Como lidar com pacientes que estejam apresentando intensa expressão de sentimentos (medo, raiva e tristeza)? Como desenvolver o tratamento de pacientes sem possibilidade de cura (aprofundando a diferença entre curar e cuidar)? Como abordar a família quando há aproximação da morte e como acolher os sentimentos presentes nesta situação? Como lidar com a expressão do desejo de morrer por parte do paciente ou da família, que não suporta ver tanto sofrimento? Como explicar para os familiares uma mudança de conduta radicalmente oposta? O que o intensivista pode falar ou não a respeito de uma decisão da qual ele não participou? O que seria eticamente correto?

\section{Conclusão}

Percebe-se que a discussão dos temas relacionados à vida, à morte e ao processo de morrer dentro das UTIs é de fundamental importância. Assim, pode-se explicar como profissionais da psicologia e da saúde mental começam a fazer parte das equipes nas UTIs, não só abrindo espaço para a discussão da morte e do processo de morrer com os membros da equipe de saúde, que frequentemente lidam com sentimentos de perda, sofrimento, dor e fracasso, mas também com os pacientes e seus familiares.

Nesse panorama, é possível perceber a importância das situações vividas por profissionais de saúde e pacientes no contexto de uma UTI.E não é difícil argumentar sobre a necessidade de mais investigação em torno das nuances, questões e desafios à capacidade humana de vivenciar complexos momentos de envolvimento com a situação da proximidade do morrer humano. É indispensável a busca da ampliação da compreensão dos processos pessoais, emocionais, existenciais, profissionais e institucionais aí envolvidos.

Não obstante, esse processo de maior compreensão e de reconhecimento da necessidade de lidar com todas as questões que surgem e que envolvem o processo de morrer deve ser trazido à tona nos espaços de formação dos profissionais de saúde. A sistematização de discussões relacionadas ao tema aqui exposto, em diferentes cenários, pode constituir um meio eficaz de articulação entre a prática vivenciada e as expectativas pessoais e profissionais de médicos, enfermeiros, fisioterapeutas, entre outros, que testemunham ou que testemunharão o complexo morrer humano.

\section{Referências}

1. Bretãs JRS, Oliveira JR, Yamaguti L. Reflexões de estudantes de enfermagem sobre morte e o morrer. Rev Esc Enferm USP. 2006;40(4):477-83.

2. Pitta A. Hospital: dor e morte como ofício. São Paulo: Hucitec; 1994. p.4.

3. Viana A, Picelli H. O estudante, o médico e o professor de medicina perante à morte e o paciente terminal. Rev Bras Educ Med. 1998;44(1):21-7.

4. Kovács MJ. Educação à morte: desafio na formação de profissionais de saúde e educação. São Paulo: Casa do Psicólogo; 2003. p.117.

5. Sousa DM, Soares EO, Costa KMS, Pacífico ALC, Parente ACM. Vivência da enfermeira no processo de morte e morrer dos pacientes oncológicos. Texto \& Contexto Enfermagem. 2009 Jan/Mar;18(1):41-7.

6. Silva GSN, Ayres JRCM. O encontro com a morte: à procura do mestre Quíron na formação médica. Rev Bras Educ Med. 2010 Oct/Dec;34(4):487-96.

7. Azeredo NSG, Rocha CF, Carvalho PRA. O enfrentamento da morte e do morrer na formação de acadêmicos de Medicina. Rev Bras Educ Med. 2011 Jan/Mar;35(1):37-43.

8. Ariés P. O homem diante da morte. Rio de Janeiro: Ediouro; 2003. p.639.

9. Kovács MJ. Educação à morte: temas e reflexões. São Paulo: Casa do Psicólogo; 2003. p.71.

10. Lock M. Twice dead: organs transplants and the reinvention of death. Berkeley: University of California Press; 2001. p.233. 
11. Torres WC. A Bioética e a Psicologia da Saúde: Reflexão sobre questões de vida e morte. Psicologia, Reflexao E Critica 2003;16(3):475-82.

12. Orlando JMC. Aspectos relacionados ao paciente: direitos do cidadão em estado crítico. In: _. UTI muito além da técnica...a humanização e a arte do intensivismo. São Paulo: Atheneu; 2001. p.43-4.

13. Baggs JG. Two instruments to measure interdisciplinary bioethical decision making. Heart Lung 1993;22(6):542-7 


\section{NORMAS DA PUBLICAÇÃO}

\section{Instruções aos autores}

A Revista HUPE considera para publicação trabalhos de revisão relacionados às ciências $d a$ saúde. Cada número versa acerca de um tema. Os artigos dos principais especialistas da área compõem o fascículo após convocação de um igualmente experiente editor convidado.

Todos os manuscritos serão avaliados por membros do corpo editorial da revista e sua aceitação para publicação dependerá de parecer técnico de revisores.

As opiniões expressas serão de exclusiva responsabilidade dos autores.

\section{Apresentação dos trabalhos}

Os autores devem seguir rigorosamente as normas editoriais da revista, particularmente no tocante ao número máximo de palavras, tabelas e figuras permitidas, bem como as regras para confecção das referências bibliográficas. É permitida a inserção de, no máximo, seis autores por manuscrito. A não observância dessas instruções implicará na devolução do manuscrito pela secretaria da revista para que os autores façam as correções pertinentes antes de submetê-lo aos revisores.

A transcrição de imagens de outras publicações deverá ter a prévia autorização dos respectivos autores para dar cumprimento às normas que regem os direitos autorais.

A Revista HUPE reserva o direto de efetuar nos artigos aceitos as adaptações de estilo gramaticais ou outras.

\section{Estrutura e preparo do manuscrito}

Os manuscritos devem ser enviados ao editor convidado por via eletrônica. O texto deve ser digitado em espaço duplo em todas as seções, com fonte Times New Roman, tamanho 12, em arquivo Word. O texto deve ter entre $2.000 \mathrm{e}$ 2.500 palavras, excluindo referências e tabelas. Deve conter no máximo cinco tabelas e/ou figuras. O número de referências bibliográficas não deve exceder a 30 .

Deve-se iniciar cada uma das seções em uma nova página: 1) página de título;2) resumo, incluindo descritores; 3) abstract, incluindo keywords; 4) texto; 5) agradecimentos; 6) referências; 7) tabelas (completas, com títulos, notas de rodapé e em páginas separadas); 8) legendas das figuras.

Página de título - Deve estar centrado no alto da folha, em destaque. Logo abaixo, colocar os nomes dos autores (como deverão ser publicados) e a afiliação, da seguinte maneira: Disciplina (se aplicável). Departamento (ou serviço). Faculdade. Universidade (ou instituição). Cidade, UF, país. Ao final, deve-se informar os dados para correspondência do autor principal (nome, endereço, telefone, e-mail).

Resumo - Deve conter obrigatoriamente de 250 a 300 palavras. Deve ser estruturado consistindo de três parágrafos. O primeiro deve descrever o objetivo da revisão, isto é, por que a revisão é relevante. $O$ segundo parágrafo descreverá os achados mais recentes e o terceiro será um resumo descrevendo 
as principais implicações dos achados na pesquisa ou prática clínica.

Abstract - Deve ser uma versão exata do resumo original para o idioma inglês.

DESCRITORES E KEYWORDS - Devem ser fornecidos de três a cinco termos em português (logo abaixo do resumo) e em inglês (logo abaixo do abstract) que definem o assunto do trabalho. Devem obrigatoriamente ser baseados nos Descritores em Ciências da Saúde (DeCS), que disponibiliza os termos em três idiomas (português, inglês e espanhol). Para consultar diretamente, acesse o endereço eletrônico: http://decs.bvs.br.

Texтo - O artigo deve conter os seguintes elementos, cada um com seu respectivo subtítulo (em folhas separadas):

Introdução - Deve conter, resumidamente, a situação atual dos conhecimentos sobre o tópico em estudo e o objetivo do estudo.

Desenvolvimento - Deve ser dividido em subtítulos conforme a necessidade do trabalho. Os dados que forem mostrados em tabelas não surgirão no texto, sendo enfatizados, no entanto, os mais importantes. Dados novos encontrados devem ser ressaltados.

Conclusões - Devem sempre estar relacionadas aos objetivos do trabalho.

Referências - Devem ser indicadas apenas as referências utilizadas nos textos. Recomenda-se o sistema sequencial, no qual as citações são numeradas na ordem de aparecimento no texto e, ao final, listadas nesta mesma ordem. O número de cada citação deve aparecer sobrescrito em fonte do mesmo tamanho que o restante do texto, sem parênteses e após pontuação, se houver. As regras para as referências devem seguir o formato Vancouver, conforme definidas pelo International Committee of Medical Journal Editors, disponível no site http://www.ncbi.nlm.nih.gov/bookshelf/br.fcgi?book=citmed. Os títulos dos periódicos citados devem ser abreviados de acordo com o estilo apresentado pela List of Journal Indexed em Index Medicus da National Library of Medicine, disponibilizada no endereço http://www. ncbi.nlm.nih.gov/entrez/journals/loftext. noprov.html. Para os artigos listados que tiverem registro DOI, o mesmo deve ser informado ao final de cada referência (conforme exemplo abaixo). Evitar incluir material não publicado e comunicações pessoais.

Para todas as referências, cite todos os autores até seis. Acima desse número, cite os seis primeiros autores seguidos da expressão ", et al.. Seguem alguns exemplos:

Artigos originais - Cummings SR, Lillington GA, Richard RJ. Estimating the probability of malignancy in solitary pulmonary nodules: a Bayesian approach. Am Rev Respir Dis. 1986;134(3):449-52. http://dx.doi.or g/10.1111/j.1600-0757.2011.00418.

Livros - Jenkins, PF. Making sense of the chest X-ray: a handbook. 2nd ed. New York: Oxford University Press; 2005. 194 p.

Capítulos de livro - Meltezer OS, Kallioniemi A, Trent JM. Cromosome alterations in human solid tumors. In: Vogelstein B, Kinzler KW, editors. The genetic basis of human cancer. New York: McGraw-Hill; 2002. p. 93-113.

Publicações oficiais - World Health Organization. Global tuberculosis control: surveillance, planning, financing. Report No. WHO/HTM/TB/2006. 362. Geneva: World Health Organization; 2006.

Endereços eletrônicos - Cancer-Pain.org [homepage on the Internet]. New York: Association of Cancer Online Resources, Inc.; c2000-01 [updated 2002 May 16; cited 2002 Jul 9]. Available from: http://www. cancer-pain.org/.

Ilustrações - Todas as ilustrações, exceto tabelas e quadros, recebem a designação de 'Figura'. Esta denominação deverá ser colocada na parte inferior da ilustração seguida do número de ordem de ocorrência no texto em algarismos arábicos, do título e 
legenda, quando houver. As figuras devem ser enviadas em arquivos separados (TIFF ou JPG, com qualidade superior de $300 \mathrm{dpi}$ ), tendo no corpo do texto sua referência de entrada.

Tabelas e quadros devem ser colocados após as referências bibliográficas. Recebem numeração independente em ordem de ocorrência no texto. A designação 'Tabela' ou 'Quadro', seguida da numeração correspondente, deverá ser colocada centralmente na parte superior da ilustração. O título da tabela ou do quadro será indicado logo abaixo em negrito e centralizado. Legendas deverão ser colocadas abaixo da tabela. Quando necessário, a fonte (autor, data e página) deverá ser citada abaixo da legenda. 